\title{
Radiance and Jacobian intercomparison of radiative transfer models applied to HIRS and AMSU channels
}

\author{
L. Garand, ${ }^{1}$ D. S. Turner, ${ }^{2}$ M. Larocque, ${ }^{1}$ J. Bates, ${ }^{3}$ S. Boukabara, ${ }^{4}$ P. Brunel, ${ }^{5}$ \\ F. Chevallier, ${ }^{6}$ G. Deblonde, ${ }^{1}$ R. Engelen, ${ }^{7}$ M. Hollingshead, ${ }^{8}$ D. Jackson, ${ }^{3}$ \\ G. Jedlovec, ${ }^{9}$ J. Joiner, ${ }^{10}$ T. Kleespies, ${ }^{11}$ D. S. McKague, ${ }^{8}$ L. McMillin, ${ }^{11}$ \\ J.-L. Moncet, ${ }^{4}$ J. R. Pardo, ${ }^{12}$ P. J. Rayer, ${ }^{13}$ E. Salathe, ${ }^{14}$ R. Saunders, ${ }^{13}$ \\ N. A. Scott, ${ }^{15}$ P. Van Delst, ${ }^{16}$ and H. Woolf ${ }^{16}$
}

\begin{abstract}
The goals of this study are the evaluation of current fast radiative transfer models (RTMs) and line-by-line (LBL) models. The intercomparison focuses on the modeling of 11 representative sounding channels routinely used at numerical weather prediction centers: 7 HIRS (High-resolution Infrared Sounder) and 4 AMSU (advanced microwave sounding unit) channels. Interest in this topic was evident by the participation of 24 scientists from 16 institutions. An ensemble of 42 diverse atmospheres was used and results compiled for 19 infrared models and 10 microwave models, including several LBL RTMs. For the first time, not only radiances but also Jacobians (of temperature, water vapor, and ozone) were compared to various LBL models for many channels. In the infrared, LBL models typically agree to within $0.05-0.15 \mathrm{~K}$ (standard deviation) in terms of top-of-the-atmosphere brightness temperature (BT). Individual differences up to $0.5 \mathrm{~K}$ still exist, systematic in some channels, and linked to the type of atmosphere in others. The best fast models emulate LBL BTs to within $0.25 \mathrm{~K}$, but no model achieves this desirable level of success for all channels. The ozone modeling is particularly challenging. In the microwave, fast models generally do quite well against the LBL model to which they were tuned. However, significant differences were noted among LBL models. Extending the intercomparison to the Jacobians proved very useful in detecting subtle or more obvious modeling errors. In addition, total and single gas optical depths were calculated, which provided additional insight on the nature of differences.
\end{abstract}

\section{Introduction}

This work represents an initiative from the International TOVS Working Group (ITWG). This group has been active in satellite meteorology since 1983 , with formal conferences organized approximately every 18 months. One of the important scientific objectives of ITWG is the optimal use of satellite data

\footnotetext{
${ }^{1}$ Meteorological Service of Canada, Dorval, Quebec, Canada. ${ }^{2}$ Meteorological Service of Canada, Downsview, Ontario, Canada. ${ }^{3}$ NOAA Environmental Research, Laboratory, Boulder, Colorado.

${ }^{4}$ Atmospheric and Environmental Research, Cambridge, Massachusetts.

${ }^{5}$ Meteo-France, Lannion, France.

${ }^{6}$ European Centre for Medium-Range Weather Forecasts, Reading, England, UK.

${ }^{7}$ Department of Atmospheric Science, Colorado State University, Fort Collins, Colorado.

${ }^{8}$ Raytheon, Aurora, Colorado.

${ }^{9}$ NASA Marshall Space Flight Center, Huntsville, Alabama.

${ }^{10}$ NASA, Greenbelt, Maryland.

${ }^{11}$ NOAA, Camp Springs, Maryland.

${ }^{12}$ California Institute of Technology, Pasadena, California.

${ }^{13}$ Met Office, Bracknell, England, UK.

${ }^{14}$ University of Washington, Seattle, Washington.

${ }^{15}$ CNRS Laboratoire de Météorologie Dynamique, Palaiseau, France.

${ }^{16}$ University of Wisconsin, Madison, Wisconsin.

Copyright 2001 by the American Geophysical Union.

Paper number 2000JD000184.

0148-0227/01/2000JD000184\$09.00
}

in global analyses in order to improve weather forecasts. Obviously, radiative transfer issues are critical in this activity, as they are in satellite remote sensing in general.

For most remote sensing applications, notably the assimilation of satellite radiances in near real time, fast and accurate forward radiative transfer models (RTMs) which simulate observed radiances are needed. In general, inversion techniques require an accompanying Jacobian routine to a given forward model. The Jacobian is the partial derivative of radiance with respect to the atmospheric parameters influencing that radiance. The Jacobian is fundamental in radiance assimilation as its magnitude and shape determine the magnitude and shape of the analysis increments (i.e., atmospheric profile corrections to a first guess [Eyre et al., 1993]). It is therefore important to evaluate both the outgoing radiance and the Jacobians.

Line-by-line (LBL) models effectively calculate the contribution of each absorbing line and hence are computationally intensive. Fast RTMs, on the other hand, are typically of the broadband (BB) monochromatic-equivalent type in that the integration over the instrument channel response is simulated directly and the transmittance is parameterized using an LBL model as reference. A third class of models, of intermediate complexity between BB and LBL, is the "narrowband" (NB). These models divide the spectrum into intervals, typically of width $1-20 \mathrm{~cm}^{-1}$ wide. The purpose of NB models is usually to calculate fluxes, taking into account the variation of the optical properties of the surface and clouds with wavelength. NB radiances can, however, be convolved with a satellite spectral 
Table 1. NOAA-14 HIRS Channel Characteristics ${ }^{\mathrm{a}}$

\begin{tabular}{|c|c|c|c|c|c|}
\hline $\begin{array}{c}\text { HIRS } \\
\text { Channel }\end{array}$ & $\nu, \mathrm{cm}^{-1}$ & $\begin{array}{c}\mathrm{NE} \Delta \mathrm{T}, \\
\mathrm{K}\end{array}$ & $\begin{array}{c}\nu \text { Range, } \\
\mathrm{cm}^{-1}\end{array}$ & Gases, K & $\underset{\mathrm{K}}{\text { BT Range, }}$ \\
\hline 2 & 679.36 & 0.44 & $672-686$ & $\mathrm{CO}_{2}, \mathrm{H}_{2} \mathrm{O}, \mathrm{O}_{3}$ & $208-239$ \\
\hline 5 & 714.50 & 0.09 & $704-724$ & $\mathrm{CO}_{2}, \mathrm{H}_{2} \mathrm{O}, \mathrm{O}_{3}$ & $225-249$ \\
\hline 9 & 1028.31 & 0.03 & $1013-1042$ & $\mathrm{O}_{3}, \mathrm{H}_{2} \overline{\mathrm{O}}, \mathrm{CO}_{2}$ & $235-295$ \\
\hline 10 & 796.04 & 0.07 & $787-805$ & $\mathrm{H}_{2} \mathrm{O}, \mathrm{O}_{3}, \mathrm{CO}_{2}$ & $242-305$ \\
\hline 11 & 1360.95 & 0.11 & $1340-1382$ & $\mathrm{H}_{2} \mathrm{O}, \mathrm{CH}_{4}, \mathrm{CO}_{2}$ & $238-268$ \\
\hline 12 & 1481.00 & 0.30 & $1441-1523$ & $\mathrm{H}_{2} \mathrm{O}, \mathrm{O}_{2}, \mathrm{CH}_{4}$ & $231-253$ \\
\hline 15 & 2236.39 & 0.06 & $2225-2248$ & $\mathrm{CO}_{2}, \mathrm{~N}_{2} \mathrm{O}, \mathrm{N}_{2}, \mathrm{H}_{2} \mathrm{O}$ & $227-263$ \\
\hline
\end{tabular}

${ }^{a}$ Channel center wavenumber $(\nu)$ and wavenumber range (approximately where normalized response function drops to 0.5 ). Instrument noise equivalent NE $\Delta T$ (prelaunch estimate at $280 \mathrm{~K}$ ). Absorbing gases are listed in decreasing order of importance. Top-of-the-atmosphere brightness temperature range for the 42 atmospheres used in this study (based on GENLN2).

response function to get a monochromatic-equivalent radiance. While, in principle, NB models should be more accurate than BB models, they are, in general, not "tuned" to fit an LBL model. Most BB models use an ensemble of predictors to compute transmittances. In most cases the regression equations require fixed pressure levels. Recently, a few BB models were developed on the basis of a physical formulation of transmittance, similar or identical to those commonly used in radiation codes computing infrared fluxes in forecast or general circulation models. These models operate on any vertical coordinate. Such physical parameterizations are also used by some NB models.

There are two main goals in this study: first, to evaluate the ability of current fast models to reproduce LBL model results and, second, to quantify the degree of agreement between LBL models themselves. In principle, LBL models using identical spectroscopic data should yield the same answer. However, LBL codes, as will be discussed further, are complex and not entirely free from approximations. Another inherent goal of this work is to present an extended methodology of validation aimed at precisely identifying the nature of the differences between models. This is accomplished by evaluating specific quantities such as level-to-TOA (top of atmosphere) transmittances and Jacobian profiles pertaining to various gases.

The U.S. National Oceanic and Atmospheric Administration (NOAA) satellites provide the ensemble of radiances most commonly used in numerical weather prediction (NWP) centers. The High-Resolution Infrared Sounder (HIRS) has 19 infrared (IR) sounding channels (from 3.8 to $15 \mu \mathrm{m}$ ), and the advanced microwave sounding unit (AMSU-A and B) has 20 microwave channels (from 23.8 to $183.31 \mathrm{GHz}$ ). This study is comprehensive, as it covers both the infrared (IR) and the microwave (MW) channels. Seven HIRS and four AMSU channels are evaluated. A very large number of plots and tables were generated from this experiment and have been made available on a web site (MSC; see acknowledgments). This paper completes the experiment with a summary of essential results.

The participation in the intercomparison was strong: 24 scientists and 29 models, including several LBLs. This reflects the interest of the modelers or model users to know the strengths and weaknesses of the model they built, maintain, or simply use as a research tool. From the viewpoint of LBL modelers especially, gaining confidence in their lengthy code is a major benefit. In fact, several modelers (including LBL) investigated early results from this study and found some deficiencies that could be corrected. Revised submissions were readily accepted since it is important to appreciate the strengths and limitations of the models when they operate as they should. However, some of the original submissions, which contained subtle or more obvious deficiencies, were retained for time considerations. The availability of LBL computations from the web site constructed for this exercise makes it possible for participants to pursue their investigation on the nature of differences.

The validation of radiance models is an ongoing process, as our knowledge of the spectroscopy improves and as new satellite channels become available. A decade ago, a major Intercomparison of Radiation Codes in Climate Models (ICRCCM) was accomplished [Ellingson et al., 1991]. The Intercomparison of Transmittance and Radiance Algorithms (ITRA) [Chedin et al., 1988] was also active for many years in radiance modeling and validation. Recently, a related validation exercise was completed by Soden et al. [2000] (hereinafter referred to as S-2000). The focus of that study was the simulation of radiances sensitive to upper tropospheric humidity. Only one channel, HIRS 12 from NOAA 12, was examined. In this paper the variety of channels studied (both IR and MW) makes the work more complex, and more emphasis is put on the validation of Jacobians. A multichannel Jacobian validation involving LBL models is in fact accomplished in this study for the first time. Section 2 defines the parameters of the experiment, and section 3 presents the various models. Sections 4 and 5 provide IR and MW results, respectively, in terms of brightness temperature (BT), Jacobians, and transmittances. Section 6 summarizes the article and suggests recommendations for future intercomparisons.

\section{Experiment Definition}

\subsection{Channel Characteristics}

The channel selection was guided by the desire to evaluate RTMs in the various spectral regions covered by HIRS and AMSU. The seven HIRS channels represent temperature sounding channels, humidity channels, and channels influenced by ozone. Three temperature channels and one water vapor channel were selected from the AMSU channels. Tables 1 and 2 show the selected HIRS and AMSU channel characteristics, respectively. The HIRS channels are those from NOAA 14, and the AMSU channels are those from NOAA 15. Planck function routines were supplied to ensure that the radiance to BT conversion is done in the same manner by all participating models. In addition, channel response functions were provided and the surface emissivity was set to unity for all IR channels and to 0.6 for all MW channels. 
Table 2. NOAA-15 AMSU Channel Characteristics ${ }^{\mathrm{a}}$

\begin{tabular}{cccccccc}
\hline AMSU & $\nu$ & Side 1 & Side 2 & $h$ band & NEST & Gases & BT Range \\
\hline 6 & 54.40 & 0.000 & 0.000 & 190.3 & 0.15 & $\mathrm{O}_{2}, \mathrm{H}_{2} \mathrm{O}$ & $217-245$ \\
10 & 57.29 & 0.217 & 0.000 & 38.29 & 0.25 & $\mathrm{O}_{2}, \mathrm{H}_{2} \mathrm{O}$ & $204-236$ \\
14 & 57.29 & 0.322 & 0.005 & 1.465 & 0.91 & $\mathrm{O}_{2}, \mathrm{H}_{2} \mathrm{O}$ & $226-272$ \\
18 & 183.31 & 1.000 & 0.000 & 250.0 & 1.06 & $\mathrm{H}_{2} \mathrm{O}, \mathrm{O}_{2}$ & $220-262$ \\
\hline
\end{tabular}

${ }^{\mathrm{a}}$ Center frequency $(\nu, \mathrm{GHz})$, first and second side bands (side 1, side $\left.2, \mathrm{GHz}\right) /$ and half bandwith $(h$ band, $\mathrm{MHz}$ ). Instrument equivalent noise $\mathrm{NE} \Delta \mathrm{T}$ (K, prelaunch measurement). Absorbing gases listed by decreasing order of importance. TOA BT range (K) for the 42 atmospheres used in this study (AER_LBL model).

\subsection{Profile Selection}

An ensemble of 42 diverse profiles was selected for the experiment. The first six are standard profiles (tropical, midlatitude summer and winter, subarctic summer and winter, and U.S. standard atmosphere [see Anderson et al., 1986]. The remaining 36 profiles were selected from a bank of profiles defined by Turner [1995a]. The 12 profiles $7-18$ are ranked by increasing mean (mass weighted) atmospheric temperature. The next $12(19-30)$ are ranked by increasing integrated water vapor, and the last $12(31-42)$ by increasing total ozone. This profile distribution should be kept in mind when interpreting results related to the profile number. Table 3 details the profile characteristics in terms of these three parameters and surface temperature. Concentrations for the following eight gases were provided: $\mathrm{H}_{2} \mathrm{O}, \mathrm{CO}_{2}$ (fixed at 360 ppmv), $\mathrm{O}_{3}, \mathrm{~N}_{2} \mathrm{O}, \mathrm{CO}, \mathrm{CH}_{4}$, $\mathrm{O}_{2}$ (fixed at $0.209 \mathrm{vol} / \mathrm{vol}$ ), and $\mathrm{N}_{2}$ (fixed at $0.781 \mathrm{vol} / \mathrm{vol}$ ). All profiles were interpolated to 43 standard pressure levels, which are the same as those used by the RTTOV (radiative transfer model for TOVS) model. These levels are listed in Table 4.

\subsection{Requested Quantities}

All participants were requested to provide for clear skies and nadir view the following quantities: (1) TOA BTs for all channels and profiles; (2) level-to-TOA total, water vapor and where appropriate, ozone transmittances (HIRS 2, 5, 9, 10) for all profiles; (3) temperature, water vapor, and where appropriate, ozone Jacobian profiles.

Jacobians were only requested to provide five profiles $(6,18$, $19,30,31)$ due to the computational load for those models that do not have the accompanying analytical Jacobian routine. For such models, Jacobians are obtained by the perturbation method, which provides an excellent approximation for small perturbations. The perturbation method is costly: a Jacobian profile is obtained from $2 N$ BT calculations where $N$ is the number of vertical levels.

The temperature Jacobian $J_{t, l}$ at level $i$ is obtained by perturbation of the temperature $T_{1}$ at that level:

$$
J_{t, l}=\mathrm{BT}\left(T_{t}+0.5 \mathrm{~K}\right)-\mathrm{BT}\left(T_{t}-0.5 \mathrm{~K}\right) .
$$

Hence the temperature Jacobian expresses the BT change at the TOA due to $1 \mathrm{~K}$ change in atmospheric temperature at a given level. Similarly, the water vapor and ozone Jacobians $J_{g, t}$ pertaining to gas $g$ were defined as

$$
J_{g, t}=\mathrm{BT}\left(q_{t}-0.05 q_{t}\right)-\mathrm{BT}\left(q_{\imath}+0.05 q_{\imath}\right),
$$

where $q_{i}$ is the specific concentration of the gas at level $i$. Thus $J_{g, l}$ is not strictly a Jacobian: the left-hand side of (2) should be divided by the perturbation $0.1 q$ to represent the Jacobian. Equation (2) represents the change in BT (units K) due to a

Table 3. Atmospheric Profile Characteristics in Terms of Surface Temperature $T_{s}$, Integrated Water Content IWC,

\begin{tabular}{|c|c|c|c|c|c|c|c|c|c|}
\hline Profile & $\begin{array}{c}T_{s}, \\
\mathrm{~K}\end{array}$ & $\begin{array}{l}\text { IWC } \\
\mathrm{kg} / \mathrm{m}^{2}\end{array}$ & $\begin{array}{l}\text { IOC, } \\
\text { DU }\end{array}$ & $\underset{\mathrm{K}}{T_{\mathrm{bar}}}$ & Profile & $\begin{array}{c}T_{\varsigma}, \\
\mathrm{K}\end{array}$ & $\begin{array}{l}\text { IWC } \\
\mathrm{kg} / \mathrm{m}^{2}\end{array}$ & $\begin{array}{l}\text { IOC, } \\
\text { DU }\end{array}$ & $\begin{array}{c}T_{\mathbf{b d r}}, \\
\mathbf{K}\end{array}$ \\
\hline 1 & 299.7 & 40.7 & 276.3 & 258.3 & 22 & 314.8 & 19.6 & 268.6 & 264.5 \\
\hline 2 & 294.2 & 29.1 & 330.5 & 258.1 & 23 & 299.5 & 22.01 & 231.1 & 259.9 \\
\hline 3 & 272.1 & 8.3 & 373.7 & 244.6 & 24 & 281.7 & 33.9 & 230.7 & 255.6 \\
\hline 4 & 287.4 & 21.0 & 343.5 & 254.0 & 25 & 292.4 & 37.3 & 270.6 & 255.7 \\
\hline 5 & 257.2 & 4.1 & 371.2 & 237.6 & 26 & 296.9 & 45.0 & 255.8 & 258.2 \\
\hline 6 & 288.2 & 14.1 & 340.2 & 250.4 & 27 & 301.4 & 52.2 & 270.7 & 259.8 \\
\hline 7 & 247.3 & 3.1 & 205.8 & 227.5 & 28 & 301.8 & 59.9 & 255.7 & 260.4 \\
\hline 8 & 242.9 & 0.6 & 484.0 & 232.2 & 29 & 298.4 & 61.5 & 217.9 & 259.2 \\
\hline 9 & 258.1 & 8.3 & 334.2 & 236.8 & 30 & 301.6 & 70.9 & 239.1 & 260.7 \\
\hline 10 & 258.1 & 3.0 & 320.6 & 238.2 & 31 & 250.5 & 1.7 & 222.5 & 232.4 \\
\hline 11 & 275.8 & 7.0 & 355.7 & 242.5 & 32 & 299.4 & 26.6 & 255.2 & 259.9 \\
\hline 12 & 277.7 & 9.7 & 343.7 & 243.1 & 33 & 296.3 & 37.3 & 276.4 & 257.6 \\
\hline 13 & 280.0 & 9.9 & 272.4 & 246.1 & 34 & 283.6 & 12.0 & 286.5 & 247.0 \\
\hline 14 & 284.3 & 15.2 & 364.1 & 251.6 & 35 & 273.3 & 7.7 & 317.0 & 244.9 \\
\hline 15 & 284.7 & 26.0 & 262.7 & 254.0 & 36 & 254.2 & 3.7 & 338.4 & 238.0 \\
\hline 16 & 285.9 & 16.6 & 242.3 & 256.5 & 37 & 261.6 & 5.2 & 371.3 & 241.1 \\
\hline 17 & 302.5 & 51.1 & 235.9 & 259.8 & 38 & 270.7 & 3.8 & 384.3 & 237.0 \\
\hline 18 & 315.9 & 33.1 & 271.3 & 263.9 & 39 & 254.1 & 2.3 & 417.9 & 234.8 \\
\hline 19 & 252.2 & 2.4 & 492.7 & 234.5 & 40 & 249.2 & 0.8 & 449.2 & 236.2 \\
\hline 20 & 290.9 & 10.2 & 235.0 & 258.1 & 41 & 253.3 & 2.0 & 470.8 & 237.0 \\
\hline 21 & 285.1 & 12.9 & 331.1 & 248.7 & 42 & 255.4 & 0.7 & 494.8 & 235.3 \\
\hline
\end{tabular}
Integrated Ozone Amount IOC, and Mean Atmospheric Temperature $T_{\text {bar }}$ 
Table 4. Vertical Coordinate Defined by 43 Pressure Levels

\begin{tabular}{|c|c|c|c|c|c|c|c|}
\hline Level & $P, \mathrm{hPa}$ & Level & $P, \mathrm{hPa}$ & Level & $P, \mathrm{hPa}$ & Level & $P, \mathrm{hPa}$ \\
\hline 1 & 0.10 & 12 & 35.11 & 23 & 253.71 & 34 & 702.73 \\
\hline 2 & 0.29 & 13 & 45.29 & 24 & 286.60 & 35 & 749.12 \\
\hline 3 & 0.69 & 14 & 56.73 & 25 & 321.50 & 36 & 795.09 \\
\hline 4 & 1.42 & 15 & 69.97 & 26 & 358.28 & 37 & 839.95 \\
\hline 5 & 2.61 & 16 & 85.18 & 27 & 396.81 & 38 & 882.80 \\
\hline 6 & 4.41 & 17 & 102.05 & 28 & 436.95 & 39 & 922.46 \\
\hline 7 & 6.95 & 18 & 122.04 & 29 & 478.54 & 40 & 957.44 \\
\hline 8 & 10.37 & 19 & 143.84 & 30 & 521.46 & 41 & 985.88 \\
\hline 9 & 14.81 & 20 & 167.95 & 31 & 565.54 & 42 & 1005.43 \\
\hline 10 & 20.40 & 21 & 194.36 & 32 & 610.60 & 43 & 1013.25 \\
\hline 11 & 27.26 & 22 & 222.94 & 33 & 656.43 & & \\
\hline
\end{tabular}

$10 \%$ change in gas specific concentration (units $\mathrm{kg} / \mathrm{kg}$ ). Such a definition is easier to interpret for this comparison. Analytical $q$ Jacobians were multiplied by $-10 \% q$ to be of the same units and sign as those obtained from (2). As defined here, temperature and water vapor Jacobians often turn out to be of similar sign and magnitude for channels sensitive to water vapor. Supersaturation does not occur in (2) as none of the profiles has levels with relative humidity beyond $95 \%$.

There are two basic causes for inaccuracy of Jacobians: inaccuracy in the forward model and error in the actual coding of the Jacobian. The coding of the perturbation method (equations (1) and (2)) is straightforward. However, errors may still occur in the interpolation from fixed levels needed by most BB models to desired output levels. Coding of an analytical Jacobian is often not trivial, but efficient ways are used by modelers to test the validity of resulting codes, including the perturbation method.

In an ideal intercomparison, Jacobians and transmittances for all intervening gases should normally have been computed, notably for $\mathrm{CO}_{2}, \mathrm{CH}_{4}, \mathrm{O}_{2}$, and $\mathrm{N}_{2} \mathrm{O}$. This is not a problem for LBL models. Even if the total transmittance in a nonmonochromatic channel is not exactly equal to the product of the individual calculated transmittances (violation of the product rule due to polychromaticity), an "equivalent" gas transmittance can be obtained [McMillin et al., 1995]. On the other hand, many of the current fast models can provide water vapor and ozone transmittances only. The effect of other gases, assumed spatially and temporally invariant, is often parameterized as a group. While $\mathrm{O}_{2}$ and $\mathrm{N}_{2}$ may be considered constant and well mixed, this is not the case for $\mathrm{CO}_{2}, \mathrm{CH}_{4}, \mathrm{~N}_{2} \mathrm{O}$, and $\mathrm{CO}$, and using climatology for these gases introduces radiative transfer errors. Other important aspects not considered in this study include the evaluation of downwelling radiances (and surface reflection), the effect of viewing angle on the accuracy of models, and vertical interpolation effects. Interpolation of transmittances from calculated to desired levels was done in optical depth space (negative of the log of transmittance). Interpolation of Jacobians was done by considering the pressure thickness of the layers. It is, in general, difficult to separate interpolation errors from other causes of error. Interpolation, if properly done, should only have a smoothing effect on the Jacobians: it should not create discontinuities.

\section{Participating Models}

The 29 participating models, $19 \mathrm{IR}$ and $10 \mathrm{MW}$, are listed in Table 5. The table specifies the model type (BB, NB, or LBL) and indicates if the model is based on a physical transmittance formulation or if it is regression based. The water vapor con- tinuum parameterization is usually taken from a version of Clough et al. [1989]. Differences between the CKD2.1 and the CKD2.2 versions are not significant for the channels studied. The spectroscopic database or the reference model on which the fast model was based is indicated. Finally, the main reference is supplied. Some additional references to those of Table 5 are provided below with a brief description of the models.

RTTOV-6 is the latest release (March 2000) of RTTOV; changes from RTTOV-5 were mainly made in the MW. This fast model has an analytic Jacobian and is widely used in the ATOVS community. OPTRAN, also used in NWP, has similar characteristics, but the vertical coordinate is the absorber space rather than a fixed pressure space. RTTOV and OPTRAN are among the fastest models: a forward calculation on 43 levels on a supercomputer takes about $5 \times 10^{-5} \mathrm{~s}$ in vectorized mode, and about 2-3 times that figure for the Jacobian. OPTRAN2 is a research version using GENLN2 as opposed to LBLRTM transmittances to derive its regression coefficients. OP-GLN2 and OP-LRTM are two additional versions of OPTRAN using different predictors and training profiles and which, again, are based on either GENLN2 or LBLRTM. MSCFAST (named AESFAST in S-2000) uses a physical formulation of transmittance based on the Goody random model (two parameters derived from the HITRAN-96 database). For each gas, a constant parameter, typically near unity, multiplies the optical depth to best fit the FLBL model. MSCFAST2 uses an additional pressure dependence factor on the optical depth affecting mostly HIRS 2 and 9. MALKMUS is another physical model based on the well-known twoparameter transmittance formulation of the same name (along with HITRAN 96). MALKMUS is not tuned to an LBL but to MODTRAN transmittances. GLATOVS [Susskind et al., 1983; Sienkiewcz, 1996], HFFP (HIRS Fast Forward Program, Joiner et al., 1998) and SIMRAD [McMillin and Fleming, 1976] are other regression models used in remote sensing. The latter is an old version that has not been modified substantially and is a narrowband model (NB) with a resolution of $1 \mathrm{~cm}^{-1}$. GLATOVS is also an old code not fully adapted for this exercise: it used the response function of corresponding HIRS channels from previous satellites to which it was adapted. STREAMER is a NB model, but its spectral resolution varies from 20 to $40 \mathrm{~cm}^{-1}$. This is a handicap for some of the channels under investigation which are narrower than this; no results were compiled for HIRS 2, 5, and 15 for that reason. The other NB model is MODTRAN, which has a nominal resolution of $2 \mathrm{~cm}^{-1}$. SYNSATRAD is classified as an LBL: it operates as such, but it evaluates spectral means to a given ac- 
Table 5. Model Characteristics ${ }^{\mathbf{a}}$

\begin{tabular}{|c|c|c|c|c|c|c|c|c|c|}
\hline & Model & From & Bands & Type & Form & $\mathrm{Jac}$ & Cont & Base & Main Reference \\
\hline 1 & RTTOV-5 & 13 & IR & BB & RG & AN & $\mathrm{C} 2.1$ & 18 & Saunders et al. [1999] \\
\hline 2 & RTTOV-6 & 13 & IR & $\mathrm{BB}$ & $\mathrm{RG}$ & AN & $\mathrm{C} 2.1$ & 18 & Saunders et al. [1999] \\
\hline 3 & OPTRAN & 11 & IR & $\mathrm{BB}$ & RG & AN & $\mathrm{C} 2.2$ & 19 & McMillin et al. [1995] \\
\hline 4 & OPTRAN2 & 11 & IR & $\mathrm{BB}$ & RG & AN & $\mathrm{C} 2.2$ & 18 & McMillin et al. [1995] \\
\hline 5 & OP-LRTM & 11 & IR & BB & RG & $\mathrm{P}$ & $\mathrm{C} 2.2$ & 19 & McMillin et al. [1995] \\
\hline 6 & OP-GLN2 & 11 & IR & $\mathrm{BB}$ & RG & $\mathbf{P}$ & $\mathrm{C} 2.2$ & 18 & McMillin et al. [1995] \\
\hline 7 & MSCFAST & 1 & IR & $\mathrm{BB}$ & $\mathrm{PH}$ & AN & $\mathrm{C} 2.1$ & 17 & Garand et al. [1999] \\
\hline 8 & MSCFAST2 & 1 & IR & $\mathrm{BB}$ & $\mathrm{PH}$ & AN & $\mathrm{C} 2.1$ & 17 & Garand et al. [1999] \\
\hline 9 & MALKMUS & 7 & IR & $\mathrm{BB}$ & $\mathrm{PH}$ & AN & $\mathrm{C} 2.2$ & H96 & Engelen and Stephens [1999] \\
\hline 10 & GLATOVS & 7 & IR & $\mathrm{BB}$ & RG & $\mathrm{AN}$ & $\mathrm{C} 2.1$ & - & Susskind et al. [1983] \\
\hline 11 & HFFP & 10 & IR & $\mathrm{BB}$ & RG & $\mathbf{P}$ & $\mathrm{C} 2.1$ & $\mathrm{H} 92$ & Joiner et al. [1998] \\
\hline 12 & SIMRAD & 9 & IR & NB & $\mathrm{RG}$ & $\mathbf{P}$ & none & - & Weinreb et al. [1981] \\
\hline 13 & STREAMER & 14 & IR & NB & PH & $\mathbf{P}$ & none & $\mathrm{H} 92$ & Key [1997] \\
\hline 14 & MODTRAN & 3 & IR & NB & $\mathrm{PH}$ & $\mathbf{P}$ & $\mathrm{C} 2.1$ & $\mathrm{H} 92$ & Berk et al. [1989] \\
\hline 15 & SYNSATRAD & 6 & IR & LBL & PH & $\mathbf{P}$ & $\mathrm{C} 2.2$ & H96 & Tjemkes and Schmetz [1997] \\
\hline 16 & $4 \mathrm{~A}$ & 15 & IR & LBL & PH & AN & $\mathrm{C} 2.1$ & G97 & Tournier et al. [1995] \\
\hline 17 & FLBL & 2 & IR & LBL & PH & $\mathbf{P}$ & $\mathrm{C} 2.1$ & H96 & Tumer $[1995 a, 1995 b]$ \\
\hline 18 & GENLN2 & 13 & IR & LBL & PH & $P$ & $\mathrm{C} 2.1$ & H96 & Edwards [1992] \\
\hline 19 & LBLRTM & 16 & IR & LBL & PH & $\mathrm{P}$ & $\mathrm{C} 2.2$ & H96 & Clough and Iacono [1995] \\
\hline 20 & RTTOV -5 & 13 & MW & $\mathrm{BB}$ & RG & AN & - & 28 & Saunders et al. $[1999]$ \\
\hline 21 & RTTOV-6 & 13 & MW & BB & RG & AN & - & 28 & Saunders et al. [1999] \\
\hline 22 & OPTRAN & 11 & MW & BB & RG & AN & - & 26 & McMillin et al. [1995] \\
\hline 23 & AER_OSS & 4 & MW & BB & RG & AN & - & 27 & Rosenkranz [1998] \\
\hline 24 & MIT & 10 & MW & $\mathrm{BB}$ & RG & $\mathbf{P}$ & - & H92 & Rosenkranz [1995] \\
\hline 25 & RAYTHEON & 8 & MW & BB & RG & $\mathrm{P}$ & - & - & Falcone et al. [1979] \\
\hline 26 & CIMSS_MWLBL & 16 & MW & LBL & PH & $\mathbf{P}$ & - & H92 & Rosenkranz [1995] \\
\hline 27 & AERLB̄ $\bar{L}$ & 4 & MW & LBL & PH & $\mathrm{P}$ & - & $\mathrm{H} 92$ & Rosenkranz [1998] \\
\hline 28 & MSCMWLBL & 1 & MW & LBL & PH & $\mathbf{P}$ & - & - & Liebe [1989], Liebe et al. [1992] \\
\hline 29 & ATM & 12 & MW & LBL & $\mathrm{PH}$ & $\mathrm{P}$ & - & H96 & Pardo et al. $[2001 \mathrm{a}, 2001 \mathrm{~b}]$ \\
\hline
\end{tabular}

${ }^{a}$ Contributing agency (column 3) designated by number in author's list. Bands are either infrared (IR) or microwave (MW) or both. Type is broadband (BB), narrowband (NB) or line by line (LBL). Transmittance formulation (form) is either regression (RG) or physical (PH). Jacobian (Jac) is either computed analytically (AN) or by the perturbation method (P). "Cont" refers to a version of the infrared $\mathrm{H}_{2} \mathrm{O}$ continuum $(\mathrm{C} 2.1$ means CKD2.1 [Clough et al., 1989]). "Base" is either the LBL reference model for fast models or the spectroscopic database (H96: HITRAN-96 [Rothman et al., 1998], G97: GEISA-97 [Jacquinet-Husson et al., 1999]).

curacy using the random sampling method, resulting in a large reduction in computer time [Tjemkes and Schmetz, 1987]. The other LBL models: FLBL, GENLN2, 4A [Scott and Chedin, 1981], and LBLRTM [Clough et al., 1992] consider all lines (with a minimum strength and within the spectral range significant for a given channel). These complex codes were all written independently, except for some shared parameterizations such as those of the continua. The year 2000 version of 4A, referred to as LBL4A_00 (N. A. Scott, private communication, 2000), was found much closer to other LBLs than the previous version (4A_93) [Tournier et al., 1995] originally submitted. Both versions of $4 \mathrm{~A}$ share the same analytical approach for the Jacobian computation [Cherny et al., 1995]. At the moment, $4 \mathrm{~A}$ is the only LBL model providing analytical Jacobians.

LBL MW models are simpler than IR models because the number of absorbing lines is less and the number of simultaneously active gases in most channels is limited to two, water vapor, and oxygen. Most models use spectroscopic data from Rosenkranz [1975, 1998], Liebe [1989], Liebe et al. [1992], and Barrett and Chung [1962]. Differences between MW LBLs may occur from different sources of line data, different water vapor and dry-air continua and different line shape formulations, including line mixing. BB MW models typically work on fixed pressure levels. No MW NB models were submitted. AER_OSS, however, uses both BB and NB concepts by doing monochromatic calculations at a set of optimally selected frequencies as predictors for band-averaged transmittance. RTTOV MW computations were based on a version of the
Liebe LBL model, which included a scalar approximation to the Zeeman effect as defined by Liebe et al. [1993]. This scalar approximation used the maximum polar value of $60 \mu T$ for the geomagnetic field for every profile. All other MW LBL model calculations did not include the Zeeman effect for this study (which only affects upper stratospheric channels), although most of them can compute it as an option.

\section{Infrared Results}

\subsection{Brightness Temperature}

Table 6 presents BT results in terms of standard deviation (SD) and bias for the seven HIRS channels. As in S-2000, GENLN2 is used as a reference. Since the SDs between LBL models are typically of the order of $0.1 \mathrm{~K}$ and at most $0.2 \mathrm{~K}$, the choice of the reference has only a marginal impact on the evaluation of the results of fast models (results versus each LBL are available on the MSC web site). The accuracy sought for fast models is $0.25 \mathrm{~K}$ or better, representing a marginal deterioration with respect to the assumed LBL accuracy $(\sim 0.10 \mathrm{~K})$ or the instrument noise NE $\Delta \mathrm{T}$ (which can be reduced by spatial averaging). Garand [2000] demonstrated the need for the highest possible RTM and measurement accuracy in radiance assimilation, considering the relatively good quality of background estimates (e.g., temperature SDs against radiosondes of the order of $0.8-1.1 \mathrm{~K}$ in the troposphere). It is also important to evaluate if the precision of the RTM deteriorates in specific types of profiles or air masses. Some of the biases listed in Table 6 exceed $2 \mathrm{~K}$. These large biases appear to be of 
Table 6. BT Standard Deviation (s.d.) and Bias (K) of Each Model Against GENLN2 for the Seven HIRS Channels ${ }^{\mathrm{a}}$

\begin{tabular}{|c|c|c|c|c|c|c|c|c|c|c|c|c|c|c|}
\hline \multirow[b]{2}{*}{ Model } & \multicolumn{2}{|c|}{$\mathrm{H}-02$} & \multicolumn{2}{|c|}{$\mathrm{H}-05$} & \multicolumn{2}{|c|}{ H-09 } & \multicolumn{2}{|c|}{ H-10 } & \multicolumn{2}{|c|}{ H-11 } & \multicolumn{2}{|c|}{ H-12 } & \multicolumn{2}{|c|}{ H-15 } \\
\hline & s.d. & Bias & s.d. & Bias & s.d. & Bias & s.d. & Bias & s.d. & Bias & s.d. & Bias & s.d. & Bias \\
\hline RTTOV-5 & 0.11 & 0.17 & 0.25 & -0.44 & 0.23 & -0.05 & 0.25 & -0.24 & $(0.42)$ & 0.16 & $(0.55)$ & 0.42 & 0.09 & -0.16 \\
\hline RTTOV-6 & 0.11 & 0.1 & 0.24 & -0.46 & 0.21 & -0.03 & 0.25 & -0.24 & $(0.42)$ & 0.16 & $(0.55)$ & 0.42 & 0.09 & -0.17 \\
\hline OPTRAN & 0.17 & 0.01 & 0.14 & 0.41 & $(1.69)$ & 1.06 & 0.09 & 0.01 & 0.18 & 0.02 & $(0.34)$ & -0.72 & 0.14 & 0.01 \\
\hline OPTRAN2 & 0.10 & -0.03 & 0.09 & -0.47 & (1.12) & -0.76 & 0.14 & -0.19 & $(1.25)$ & 0.12 & 0.11 & -0.48 & 0.07 & -0.31 \\
\hline OP-GLN2 & 0.20 & 0.03 & $(0.52)$ & -0.62 & 0.19 & 0.23 & 0.13 & -0.18 & $(1.00)$ & -3.38 & 0.16 & -0.64 & $(0.45)$ & -1.28 \\
\hline OP-LRTM & 0.09 & -0.05 & 0.11 & 0.58 & $(1.45)$ & 0.79 & 0.08 & -0.02 & $(0.92)$ & -2.83 & $(0.27)$ & -0.71 & 0.20 & 0.14 \\
\hline MSCFAST & $(0.48)$ & 0.06 & 0.23 & -0.57 & $(0.46)$ & 0.03 & 0.07 & -0.03 & 0.12 & -0.10 & 0.08 & 0.05 & 0.21 & 0.18 \\
\hline MSCFAST2 & 0.10 & -0.05 & 0.22 & -0.61 & $(0.31)$ & 0.03 & 0.07 & -0.03 & 0.12 & -0.10 & 0.08 & 0.05 & 0.21 & 0.15 \\
\hline MALKMUS & $(0.56)$ & 0.82 & $(0.36)$ & 0.54 & $(0.86)$ & 1.67 & $(0.55)$ & 0.78 & $(0.49)$ & 2.27 & 0.24 & 0.58 & $(0.36)$ & 0.41 \\
\hline GLATOVS & $(0.60)$ & -0.90 & $(0.65)$ & 2.44 & $(0.92)$ & -0.95 & (0.41) & -1.18 & $(0.85)$ & 0.23 & $(0.72)$ & -0.78 & $(0.41)$ & 0.49 \\
\hline HFFP & 0.06 & -0.01 & $(0.26)$ & -0.05 & $(0.57)$ & 0.13 & (1.36) & 0.09 & 0.14 & -0.09 & 0.07 & -0.23 & 0.11 & -0.28 \\
\hline SIMRAD & 0.26 & -0.49 & $(0.74)$ & -1.26 & $(5.08)$ & 18.36 & (1.03) & -1.18 & $(1.14)$ & -0.38 & $(1.61)$ & 2.60 & $(0.60)$ & 2.35 \\
\hline STREAMER & $\cdots$ & $\cdots$ & $\ldots$ & $\ldots$ & $(1.32)$ & 4.22 & $(0.45)$ & 0.05 & $(0.85)$ & 2.47 & $(0.29)$ & 0.49 & $\cdots$ & $\cdots$ \\
\hline MODTRAN & 0.05 & 0.03 & $(0.70)$ & -1.49 & $(0.51)$ & -0.78 & 0.04 & -0.16 & 0.08 & -0.35 & 0.19 & -0.02 & $(0.41)$ & -0.15 \\
\hline SYNSATRAD & 0.16 & -0.25 & 0.14 & -0.21 & $(0.58)$ & 0.49 & 0.03 & 0.04 & 0.13 & 0.05 & 0.06 & 0.11 & $\ldots$ & $\ldots$ \\
\hline FLBL & 0.12 & -0.15 & 0.14 & -0.50 & 0.06 & -0.01 & 0.04 & 0.02 & 0.04 & -0.08 & 0.15 & -0.14 & 0.06 & 0.11 \\
\hline LBL4A 00 & 0.04 & -0.15 & 0.03 & -0.08 & 0.06 & 0.02 & 0.09 & 0.01 & 0.06 & -0.25 & 0.13 & -0.14 & 0.06 & 0.05 \\
\hline LBLRTM & 0.05 & -0.05 & 0.10 & 0.36 & 0.05 & 0.12 & 0.06 & 0.04 & 0.06 & -0.08 & 0.19 & -0.16 & 0.09 & 0.18 \\
\hline
\end{tabular}

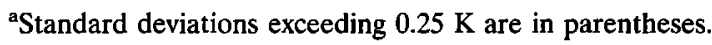

a systematic nature: GLATOVS, SIMRAD, and MODTRAN in HIRS 05; MALKMUS, STREAMER, OP_GLN2, and OP_LRTM in HIRS 11. Biases of that magnitude may be caused by not tuning the fast models to a reference LBL model, spectral resolution that is too coarse, outdated spectroscopy, neglecting a contributing gas, incorrect convolution with the spectral response function, or some implementation error.

RTTOV achieves the desired accuracy in most channels except for the water vapor channels 11-12 (SDs 0.42-0.55 K). It appears that RTTOV would benefit from an improved water vapor transmittance. The various versions of OPTRAN give accurate results in all channels, but no single version does this. For example, the "official" OPTRAN gets poor results in HIRS- 09 due to the fact that only six different ozone profiles were used in the dependent atmospheres, but OP_GLN2 solves this problem with a more representative ensemble of training profiles. OPTRAN2, based on GENLN2, is slightly closer to that reference in HIRS 02,5 , and 15 , and more significantly in HIRS 12 . Thus the fast models appear to be sensitive to the reference that they are tuned against as well as to the choice of dependent atmospheres. The more advanced version of MSCFAST, MSCFAST2, gets very good results in most channels, notably water vapor channels. A weaker channel is HIRS 09, where MSCFAST2 has a BT SD of $0.31 \mathrm{~K}$. The other physical model, MALKMUS, gets SDs in the range 0.240.68 except in HIRS 09. MALKMUS would probably gain from a direct tuning of its transmittances to an LBL model. GLATOVS and SIMRAD are older codes, which would require significant adjustments to be used in NWP. HFFP yields excellent results in five of the seven channels, with degraded performance in HIRS 09 and 10. SYNSATRAD obtains results similar to full LBLs, except in HIRS 09 where its ozone transmittance was found deficient (i.e., the sampling of ozone lines most likely requires revision). In general, BB and NB models often get excellent results, better than $0.25 \mathrm{~K}$, but no such model is fully satisfactory in all respects. Fast models with transmittance formulation tuned to an LBL reference tend to be more accurate than the models that were not adjusted that way.

A look at individual differences often reveals specific error characteristics. Figure 1 shows BT differences with respect to
GENLN2 of selected fast models for the 42 atmospheres and for 6 of the HIRS channels. The HIRS-02 plot shows the large improvement of MSCFAST2 (SD of $0.10 \mathrm{~K}$ ) over MSCFAST (SD of $0.48 \mathrm{~K}$ ) and the $0.5 \mathrm{~K}$ bias associated to SIMRAD. HIRS 05 is characterized by two groups of models, each about $\pm 0.5 \mathrm{~K}$ off from GENLN2. Models based on LBLRTM, like OP LRTM and OPTRAN, have a positive bias. Others, based on FLBL (MSCFAST2) or GENLN2 (RTTOV-6, OPTRAN2) have a negative bias. HIRS 09 is the channel with largest spread among models. STREAMER has a large positive bias with important fluctuations in dry atmospheres. MALKMUS, OPTRAN, and GLATOVS are also erratic. In HIRS 10, differences pertaining to MALKMUS are clearly higher in warm and wet profiles $(17-18,22-30)$. The same is true for RTTOV-6, with less amplitude and opposite sign: differences are higher in profiles with integrated water content greater than $35 \mathrm{~kg} \mathrm{~m}^{-2}$. STREAMER gets largest differences in the two warmest profiles, 18 and 22. In HIRS 11, MALKMUS has a relatively uniform $2.5 \mathrm{~K}$ bias but also exhibits peaks far from that mean value in the driest atmospheres: $8,19,31$, and 42 . In contrast to HIRS 10, RTTOV-6 differences appear random in HIRS 11 as well as in HIRS 12. In the latter channel, OP_GNLN2 represents a significant improvement over OPTRAN, but the $\sim 0.7 \mathrm{~K}$ bias remains. MSCFAST2 and HFFP are closest to GENLN2, with SDs as low as $0.08 \mathrm{~K}$ in HIRS 12.

A more detailed examination of LBL results is of interest. Understanding the cause of differences between LBL models is a complicated issue. Differences may be caused by factors such as spectroscopy, continuum parameterizations, methods of integrating vertically and spectrally, accounting of pressure and temperature effects, interpolation into precomputed tables, and spectral resolution $\left(0.005 \mathrm{~cm}^{-1}\right.$ is typical). As in Figure 1, Figure 2 shows BT differences between four LBL models and GENLN2 for the seven HIRS channels as a function of the profile number. In HIRS 05 , nearly constant $-0.5 \mathrm{~K}$ differences are noted for FLBL and +0.4 K for LBLRTM. As noted in Figure 1, this bias structure is reproduced by fast models. Excellent agreement is seen in HIRS 09, except for SYNSATRAD. Differences for that model were found to in- 

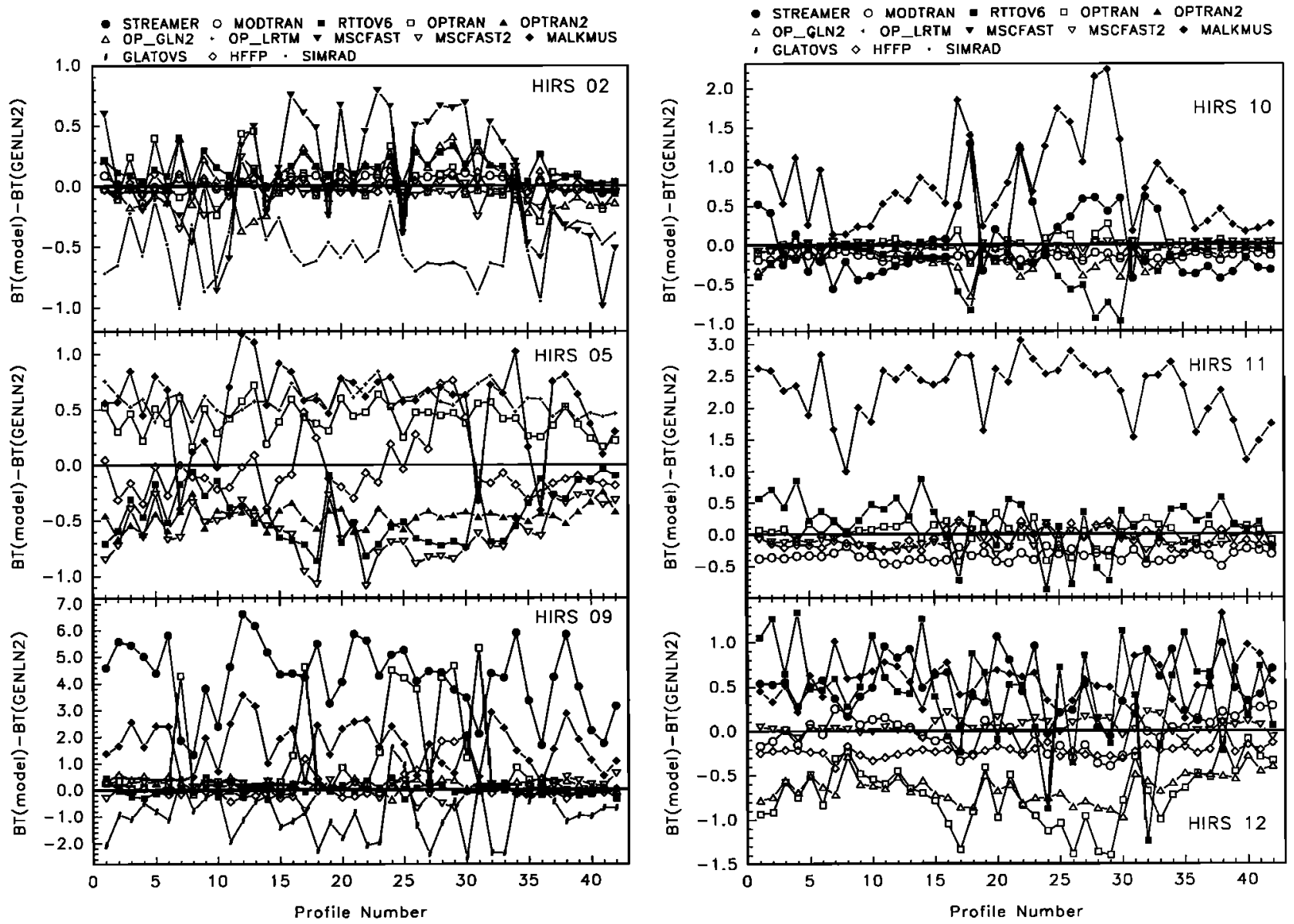

Figure 1. Brightness temperature (BT) difference (K) between selected fast models (identified by symbols) and GENLN2 as a function of the atmospheric profile number for HIRS 2, 5, and 9-12.

crease with higher BTs. Differences up to $0.3 \mathrm{~K}$ in HIRS 10 of LBLAA 00, FLBL, and LBLRTM are clearly linked to the warmest and wettest profiles. In HIRS 11, LBLAA has a nearly uniform $-0.25 \mathrm{~K}$ bias, and SYNSATRAD has largest differences in cold atmospheres (7-10, 31, 36). In HIRS 12, GENLN2 is the outsider (differences up to $-0.55 \mathrm{~K}$ ), with all other models packed together. Attempts to explain this discrepancy have not been successful yet, but the larger differences in warm atmospheres suggest temperature effects. The continuum parameterization is not a probable candidate for the differences since other LBLs used either the same one or a very similar version. In HIRS 15, LBLRTM and FLBL differ from GENLN2 in a similar fashion, with biases up to $0.3 \mathrm{~K}$, again larger in warmer atmospheres. Thus, in general, LBL differences as large as $0.5 \mathrm{~K}$ are often noted in HIRS channels, some of uniform nature, others more linked to the temperature structure. A more detailed investigation involving optical depth differences pertaining to individual gases would reveal additional information on the nature of differences. Some examples are provided in the next section.

\subsection{Jacobians and Transmittances}

To objectively evaluate Jacobians, a goodness of fit measure, $M$, was defined as

$$
M=100 \sqrt{\frac{\sum_{t=1}^{N}\left(J_{m, l}-J_{r, l}\right)^{2}}{\sum_{t=1}^{N} J_{r, l}^{2}}},
$$

where $J_{m}$ and $J_{r}$ are the model and reference Jacobian, respectively, and the sum is over the number of levels, $N$. This measure can be seen as an overall percentage of error. With this normalization, values of $M$ can be interpreted in a similar fashion for all channels. In practice, it is found that values of $M$ below 5 indicate an excellent Jacobian fit, typical among LBL models; $5<M<15$ indicates a good fit, probably sufficient for NWP application; $15<M<25$ is fair to marginal, and $M>25$ indicates a serious problem. This measure is only indicative; visual inspection of the profiles certainly gives more clues on the nature of problems. Examination of Jacobians associated with a single profile is sufficient for illustration purposes. Profile 30 was chosen; it is a warm and wet profile. Table 7 provides $M$ values for profile 30 and for the various channels associated with either temperature, water vapor, or ozone $\mathrm{Ja}$ cobian profiles.

Representative HIRS Jacobian profiles are shown in Plate 1. 


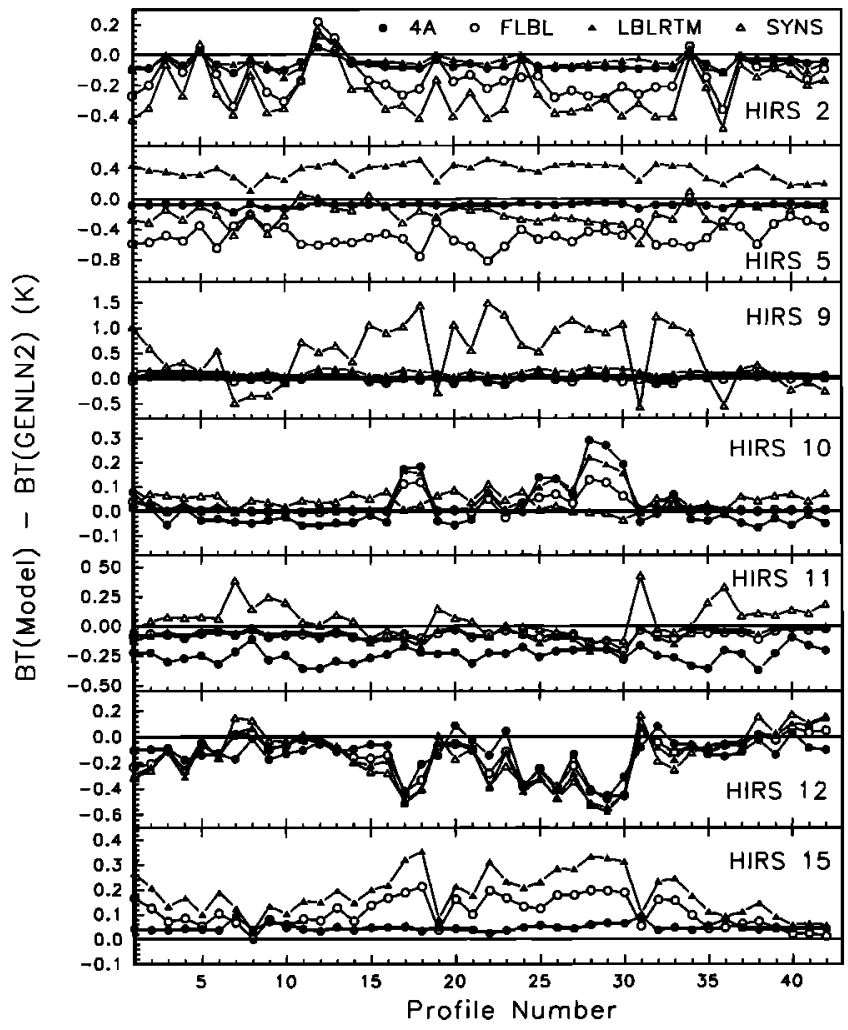

Figure 2. BT difference (K) between IR LBL models (identified by symbols) and GENLN2 as a function of the atmospheric profile number for the seven HIRS channels.

The figure allows to appreciate the spread between the various models and to identify outsiders. One can link the $M$ values in Table 7 and the Jacobian profile characteristics in Plate 1. GLATOVS produces some unphysical kinks in three of the profiles in Plate 1. Profiles with kinks or noise will no doubt make convergence more difficult in data assimilation. An erratic behavior is also noted for OP-GLN2 in the HIRS-05 T Jacobian and for MODTRAN in the HIRS-10 plot. Ozone Jacobians for HIRS 09 are clearly exaggerated for OPTRAN and OP-LRTM, resulting in large $M$ values. These two models also display some spurious oscillations above $100 \mathrm{hPa}$ in the HIRS-11 $\mathrm{H}_{2} \mathrm{O}$ Jacobians. This result may point to a weak conditioning of the regression at upper levels. This type of error is probably easy to eliminate. HFFP is an outsider in HIRS-05 T, and especially in HIRS- $10 \mathrm{H}_{2} \mathrm{O}(M=60.7)$ due to a reduced Jacobian amplitude. The RTTOV Jacobian amplitude and to some degree the peak position (notably for HIRS-10 $\mathrm{H}_{2} \mathrm{O}$ ) differ from the others in the HIRS 10, 11, and 15 plots, resulting in $M$ values in the range 12-18. Finally, the amplitude peak and position of HIRS-15 $\mathrm{T}$ Jacobians are slightly off for MSCFAST and MALKMUS. These few examples show that the Jacobian study allows the determination of minor and even more serious problems which otherwise would have been difficult to detect. Values of $M$ for LBLs are typically less than 10 . Somewhat higher values are noted for LBL4A_00. Jacobians for that LBL were found to have the right shape and amplitude but with peaks slightly too high $(\sim 20 \mathrm{hPa})$ because of their evaluation in the middle of the layers (rather than at their boundaries). Except for the ozone Jacobian in HIRS 05, SYNSATRAD is remarkably close to GENLN2, with all values of $M$ below 6.5 in Table 7 .

A look at individual gas transmittances reveals specific information on the nature of differences. As an example, ozone transmittances are shown in Plate 2 for HIRS 5 and 9. The spread becomes large below $50 \mathrm{hPa}$. RTTOV, GLATOVS, SYNSATRAD, and MALKMUS appear as outsiders in HIRS 05, while the same applies again to the latter three models, MSCFAST and MODTRAN in HIRS 09. The OPTRAN and OP-LRTM transmittances become abruptly constant below 200 mbar, which should not be the case. MODTRAN displays transmittances slightly increasing with pressure, which is nonphysical. In general, outsiders in $\mathrm{O}_{3}$ transmittance are linked to largest $\mathrm{O}_{3}$ Jacobian $M$ values in Table 7, as well as largest BT SDs in Table 6.

Scatterplots of individual model optical depths versus GENLN2 optical depths (from each level to the TOA) are shown in Figure 3 for HIRS 11. This is a very convenient way to appreciate the quality of a transmittance formulation. GLATOVS has a low optical depth bias, but the scatter is

Table 7. Goodness of Fit Measure $M$ (No Units) for Temperature $(T)$, Ozone $\left(\mathrm{O}_{3}\right)$, or Water Vapor $\left(\mathrm{H}_{2} \mathrm{O}\right)$ Jacobians for Atmospheric Profile 30 in HIRS Channels ${ }^{\text {a }}$

\begin{tabular}{|c|c|c|c|c|c|c|c|c|c|c|c|c|c|}
\hline Model & $\begin{array}{c}\mathrm{H}-02 \\
T \\
\end{array}$ & $\begin{array}{c}\mathrm{H}-05 \\
T \\
\end{array}$ & $\begin{array}{c}\mathrm{H}-05 \\
\mathrm{O}_{3}\end{array}$ & $\begin{array}{c}\mathrm{H}-09 \\
T\end{array}$ & $\begin{array}{l}\mathrm{H}-09 \\
\mathrm{H}_{2} \mathrm{O}\end{array}$ & $\begin{array}{c}\mathrm{H}-09 \\
\mathrm{O}_{3}\end{array}$ & $\begin{array}{c}\mathrm{H}-10 \\
T\end{array}$ & $\begin{array}{l}\mathrm{H}-10 \\
\mathrm{H}_{2} \mathrm{O}\end{array}$ & $\begin{array}{c}\mathrm{H}-11 \\
T\end{array}$ & $\begin{array}{l}\mathrm{H}-11 \\
\mathrm{H}_{2} \mathrm{O}\end{array}$ & $\begin{array}{c}\mathrm{H}-12 \\
T\end{array}$ & $\begin{array}{l}\mathrm{H}-12 \\
\mathrm{H}_{2} \mathrm{O}\end{array}$ & $\begin{array}{c}\mathrm{H}-15 \\
T\end{array}$ \\
\hline RTTOV-5 & 3.3 & 4.5 & 24.6 & 10.5 & 2.9 & 21.8 & 8.3 & 12.1 & 8.0 & 16.5 & 17.8 & 15.6 & 2.7 \\
\hline RTTOV-6 & 2.9 & 4.4 & 23.8 & 10.0 & 3.0 & 21.5 & 8.3 & 12.1 & 8.0 & 16.6 & 17.8 & 15.6 & 2.7 \\
\hline OPTRAN & 4.6 & 6.8 & (30.6) & 7.8 & 5.2 & (226.1) & 7.8 & 2.9 & 4.5 & 13.0 & 8.2 & 20.6 & 5.8 \\
\hline OPTRAN2 & 2.5 & 4.9 & (46.4) & 21.9 & 5.4 & $(30.7)$ & 7.6 & 3.0 & 4.0 & 5.0 & 6.9 & 8.4 & 2.4 \\
\hline OP-GNLN2 & 7.9 & 20.9 & (121.6) & 7.3 & 3.4 & (60.7) & 6.3 & 3.4 & 23.6 & 20.7 & 7.2 & 12.9 & 5.8 \\
\hline OP-LRTM & 3.0 & 7.1 & $(28.0)$ & 8.1 & 4.7 & (138.5) & 6.1 & 3.1 & 21.2 & 21.6 & 8.0 & 12.5 & 7.2 \\
\hline MSCFAST & 11.9 & 6.5 & 13.9 & 6.1 & 8.4 & $18.9^{\prime}$ & 1.8 & 1.8 & 5.4 & 6.8 & 8.0 & 9.2 & 7.7 \\
\hline MSCFAST2 & 3.7 & 6.0 & 13.7 & 7.3 & 5.9 & 13.1 & 1.8 & 1.8 & 5.4 & 6.8 & 8.0 & 9.2 & 7.7 \\
\hline MALKMUS & 9.1 & 7.1 & (29.4) & 16.5 & 13.3 & (30.5) & 16.1 & 11.8 & 11.1 & 10.9 & 10.9 & 14.1 & 9.1 \\
\hline GLATOVS & 14.4 & 24.4 & (25.0) & 22.1 & 21.3 & (70.4) & 23.5 & $(26.2)$ & 8.2 & 22.3 & 7.4 & 16.6 & 10.7 \\
\hline HFFP & 7.9 & 16.0 & 9.7 & $(57.3)$ & $(78.8)$ & 19.1 & $(41.0)$ & $(60.7)$ & 6.3 & 10.1 & 8.8 & 10.3 & 3.3 \\
\hline STREAMER & $\ldots$ & $\cdots$ & $\cdots$ & 18.6 & 11.7 & $\cdots$ & 4.8 & 2.3 & 13.4 & 17.5 & 9.4 & 8.1 & $\cdots$ \\
\hline SYNSATRAD & 2.9 & 6.3 & 20.4 & 4.2 & 3.6 & 3.0 & 1.9 & 1.0 & 3.8 & 2.6 & 6.4 & 5.0 & .. \\
\hline MODTRAN & 3.9 & 12.9 & 15.2 & 16.3 & 19.1 & 9.2 & 11.0 & 15.8 & 4.7 & 3.7 & 7.0 & 4.3 & 5.2 \\
\hline FLBL_00 & 6.4 & 10.8 & 2.6 & 8.5 & 1.4 & 2.7 & 2.1 & 1.7 & 4.0 & 6.4 & 8.3 & 11.8 & 9.3 \\
\hline LBLAĀ__00 & 7.3 & 8.2 & 16.5 & 11.5 & 12.5 & 12.3 & 9.5 & 11.3 & 16.6 & 17.9 & $(27.0)$ & (28.4) & 7.0 \\
\hline LBLRTM & 4.7 & 7.7 & 3.8 & 8.3 & 4.7 & 0.7 & 2.2 & 2.7 & 4.4 & 4.2 & 8.2 & 5.4 & 8.6 \\
\hline
\end{tabular}

${ }^{a}$ GENLN2 was used as reference. Values above 25 are in parentheses. 

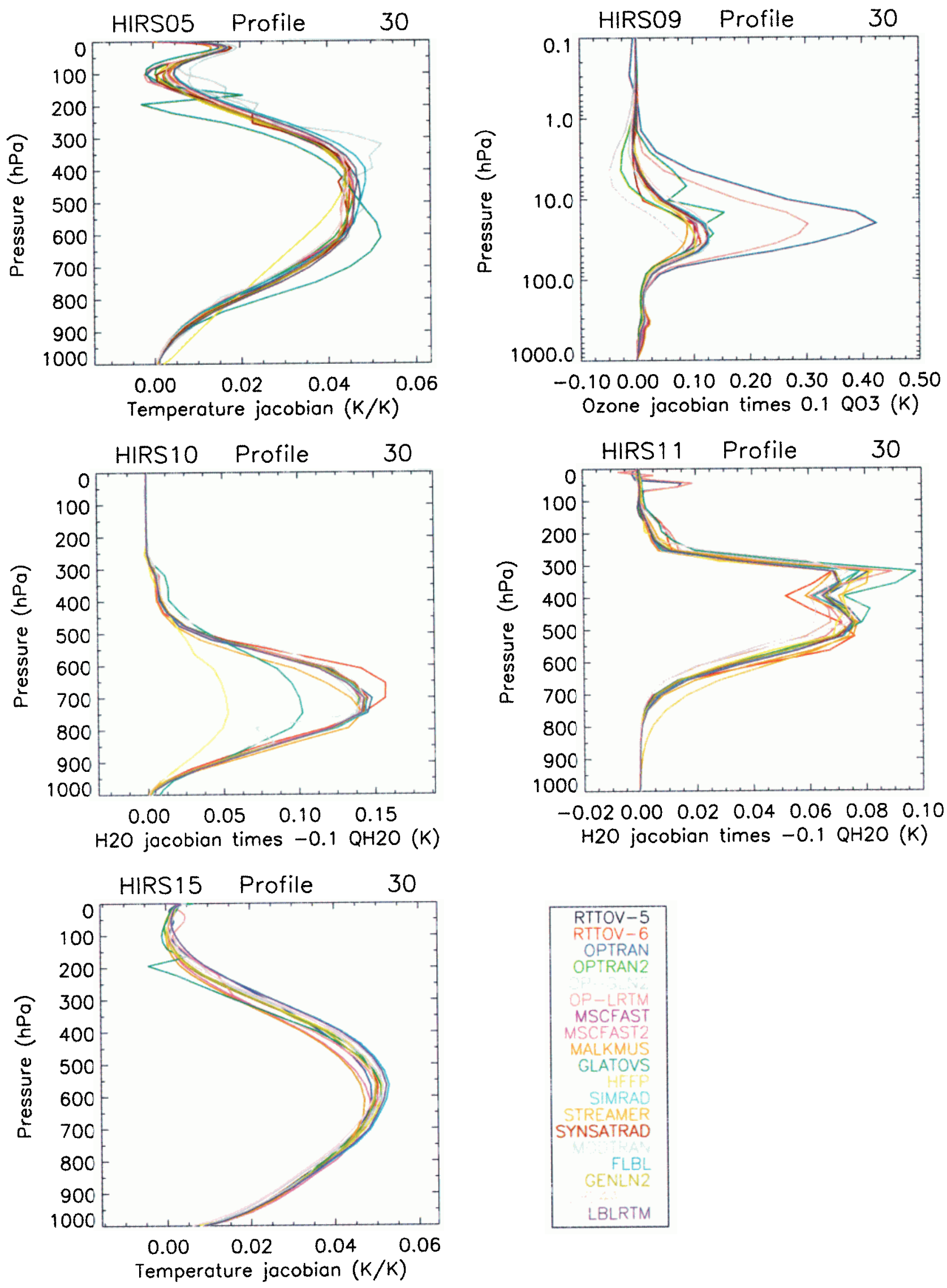

Plate 1. HIRS-05 T, HIRS-09 $\mathrm{O}_{3}$, HIRS-10 and HIRS- $11 \mathrm{H}_{2} \mathrm{O}$, and HIRS-15 T Jacobian profiles for the various IR models applied to atmospheric profile 30 . 

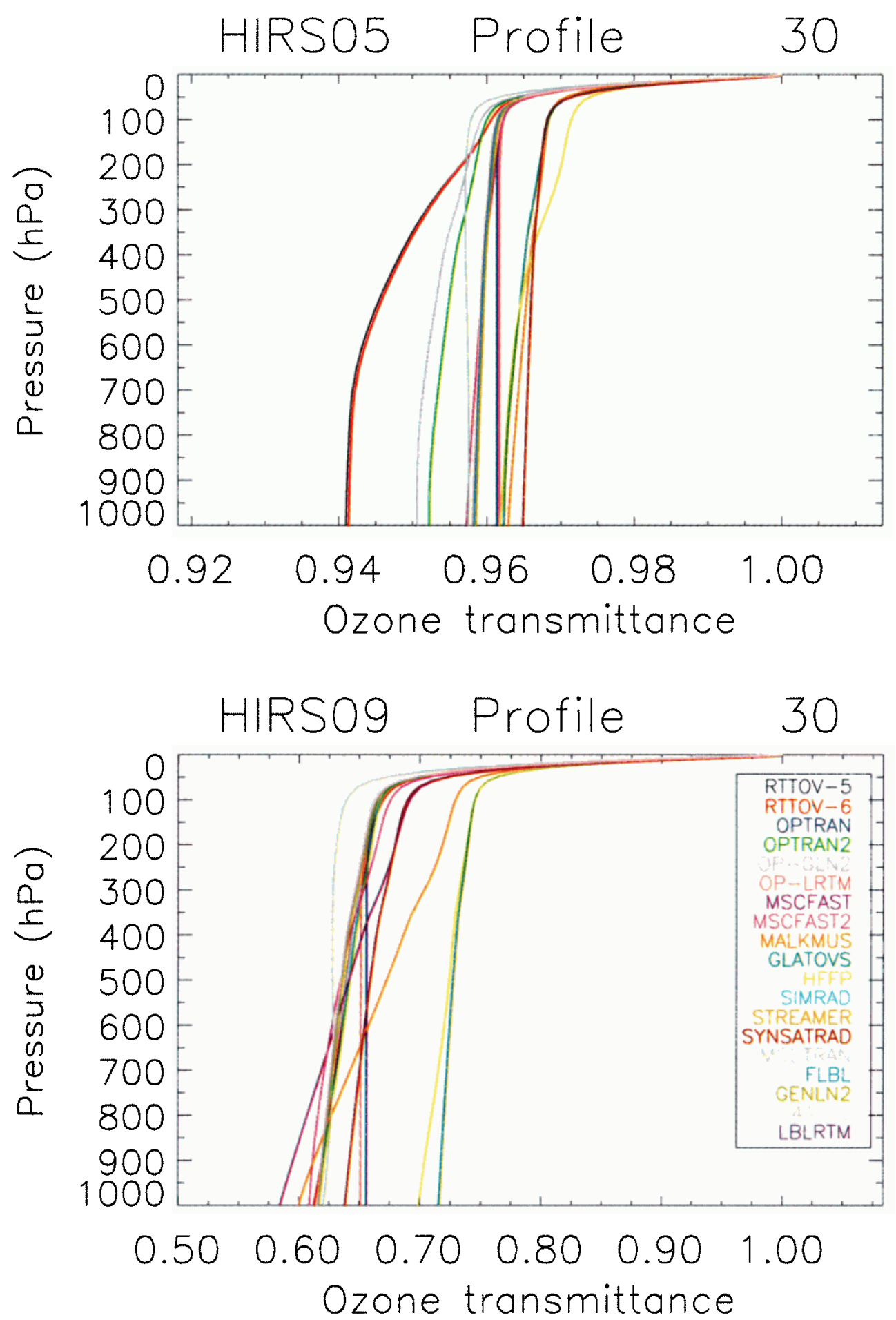

Plate 2. (a) HIRS-05 and (b) HIRS-09 ozone top-of-atmosphere (TOA) transmittance for various infrared models and atmospheric profile 30 . For reference the GENLN2 surface to $\mathrm{TOA} \mathrm{O}_{3}$ transmittance is 0.958 in HIRS 05 and 0.616 in HIRS 09 .

large. Among the fast models, OPTRAN is clearly the model closest to GENLN2; its scatter is very small. MODTRAN also displays a small scatter, but its optical depths are underestimated. A simple multiplication of optical depths by a constant would remove most of that bias. High scatter, on the other hand, can only be reduced by major changes to the transmittance formulation. FLBL follows GENLN2 almost exactly. The somewhat larger scatter of LBL4A_00 suggests that this model differs the most from other LBLs for water vapor transmittances. Since this scatter has no bias while that of total transmittance (not shown) indicates a slight overestimation of optical depths, one may speculate that the negative LBL4A $00 \mathrm{BT}$ constant bias of $-0.25 \mathrm{~K}$ (Figure 2) is caused by the second gas in importance: methane. This hypothesis could be ascertained by a look at methane transmittances, which were not available for this study. 

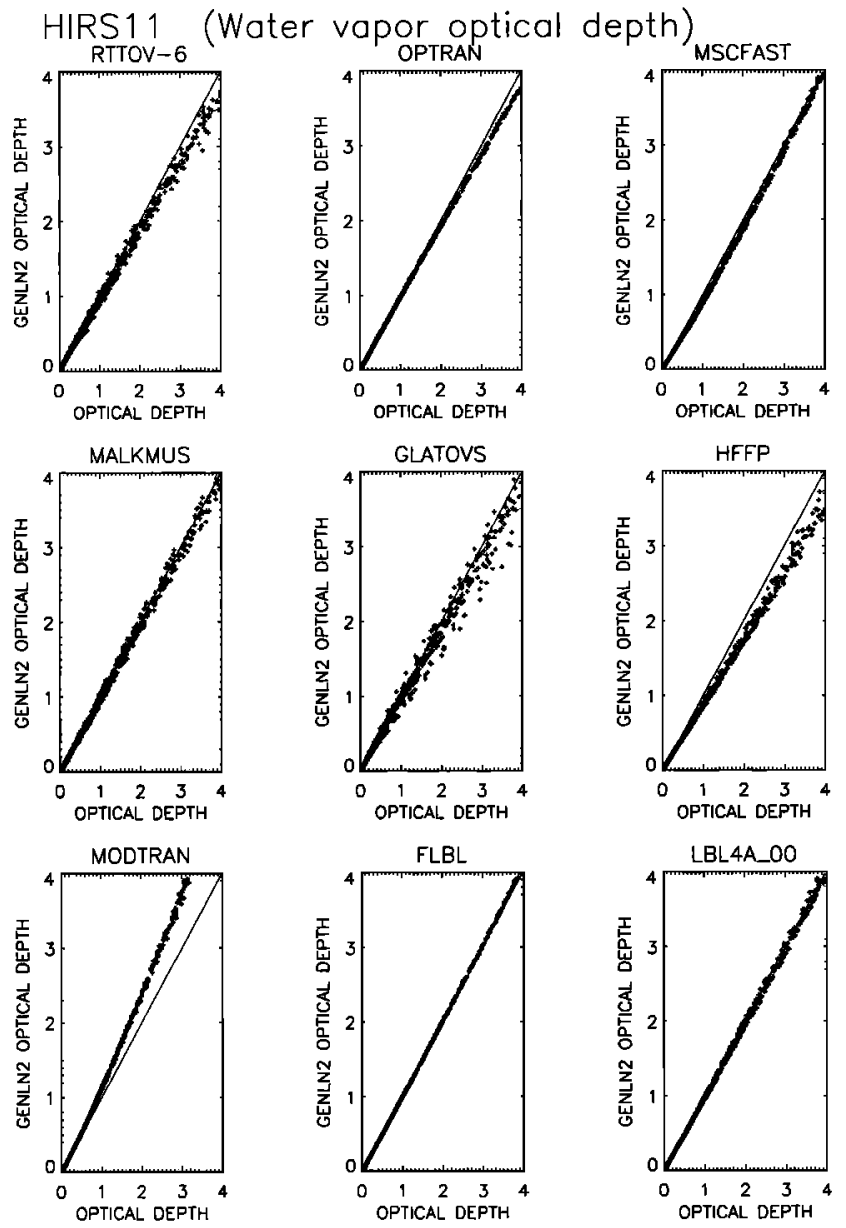

Figure 3. Scatterplot of HIRS-11 GENLN2 TOA optical depths versus those of the other IR models obtained from all profiles and levels.

\section{Microwave Results}

\subsection{Brightness Temperatures}

Table 8 lists the microwave BT SDs and biases, using CIMSS_MWLBL as the reference. This LBL model is in excellent agreement with AER_LBL and in relatively good agreement with ATM. AER_OSS is derived from AER_LBL and these two models are within $0.05 \mathrm{~K}$ of each other for all four channels. ATM shows some significant differences with CIMSS_MWLBL in two channels: $0.19 \mathrm{~K} \mathrm{BT} \mathrm{SD} \mathrm{in}$

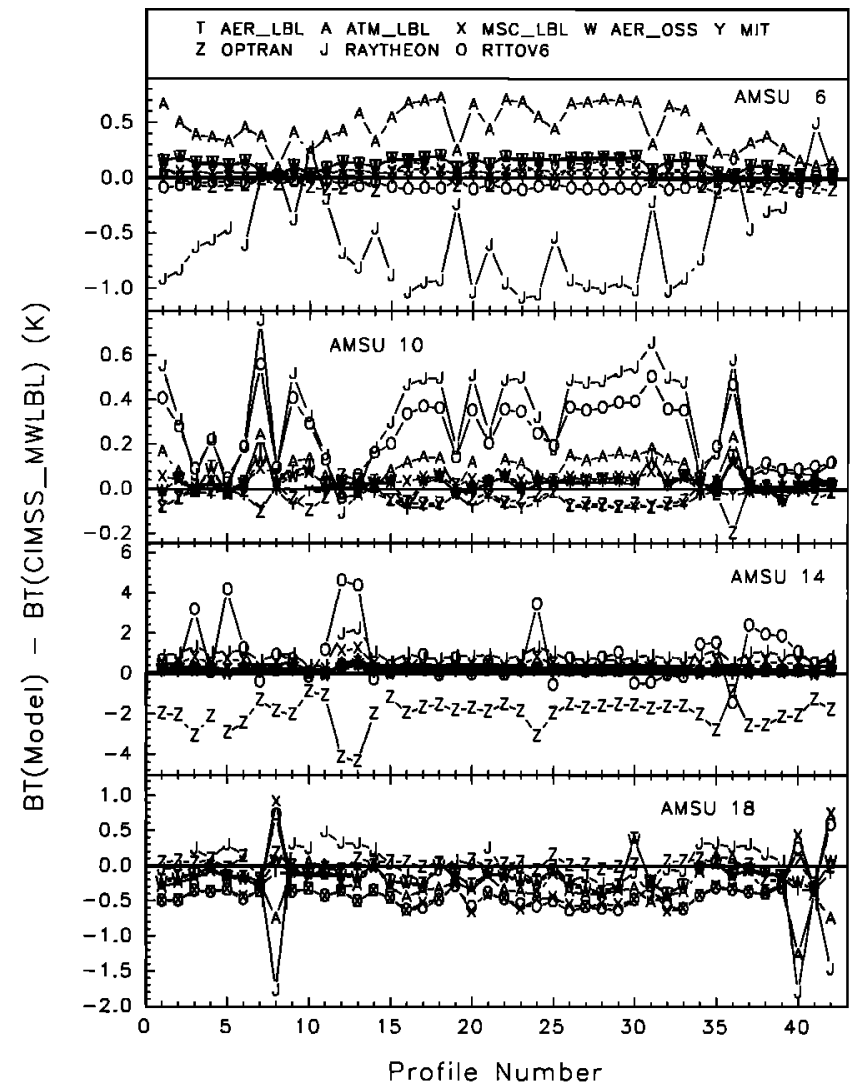

Figure 4. BT difference $(\mathrm{K})$ between microwave models and CIMSS MWLBL as a function of the atmospheric profile number for the four AMSU channels. RTTOV-5, similar to RTTOV-6, is not shown.

AMSU 06 and $0.24 \mathrm{~K}$ in AMSU 18. In general, the largest differences between LBL models are seen in AMSU 18, the water vapor channel. A large SD of $1.35 \mathrm{~K}$ is seen in AMSU 14 for RTTOV-5 and 6 (see below for explanation).

Figure 4 shows the BT difference in the four AMSU channels between various MW models and CIMSS_MWLBL as a function of profile number. In AMSU-06, ATM has a systematic bias of about $0.5 \mathrm{~K}$. RAYTHEON appears deficient in that channel, with highly variable BT differences. Other models are very close, typically within $0.1 \mathrm{~K}$ SD. In AMSU 10, RTTOV-6 and RAYTHEON display similar difference characteristics, with amplitudes as large as $0.7 \mathrm{~K}$. Differences do not seem

Table 8. BT Standard Deviation (K, First Line) and Bias (K, Second Line) of Various Models Against CIMSS_MWLBL for Four Microwave Channels ${ }^{\mathrm{a}}$

\begin{tabular}{|c|c|c|c|c|c|c|c|c|}
\hline \multirow[b]{2}{*}{ Model } & \multicolumn{2}{|c|}{ AMSU 06} & \multicolumn{2}{|c|}{ AMSU 10} & \multicolumn{2}{|c|}{ AMSU 14} & \multicolumn{2}{|c|}{ AMSU 18} \\
\hline & s.d. & Bias & s.d. & Bias & s.d. & Bias & s.d. & Bias \\
\hline RTTOV-5 & 0.04 & -0.05 & 0.14 & 0.25 & $(1.35)$ & 0.91 & $(0.60)$ & -0.16 \\
\hline RTTOV-6 & 0.04 & -0.05 & 0.14 & 0.25 & (1.35) & 0.91 & $(0.28)$ & -0.38 \\
\hline OPTRAN & 0.09 & 0.00 & 0.05 & -0.04 & $(0.73)$ & -1.97 & 0.10 & 0.00 \\
\hline AER OSS & 0.06 & 0.13 & 0.04 & 0.03 & 0.09 & 0.14 & 0.14 & -0.16 \\
\hline $\mathrm{MIT}^{-}$ & 0.01 & 0.00 & 0.04 & -0.04 & 0.08 & -0.09 & 0.19 & -0.40 \\
\hline RAYTHEON & $(0.42)$ & -0.57 & 0.17 & 0.24 & 0.20 & 0.60 & $(0.50)$ & -0.07 \\
\hline AER_LBL & 0.06 & 0.13 & 0.05 & 0.03 & 0.09 & 0.16 & 0.14 & -0.15 \\
\hline MSCMWLBL & 0.03 & 0.05 & 0.03 & 0.04 & 0.20 & 0.51 & $(0.32)$ & -0.36 \\
\hline ATM & 0.19 & 0.46 & 0.07 & 0.08 & 0.11 & 0.23 & 0.24 & -0.28 \\
\hline
\end{tabular}

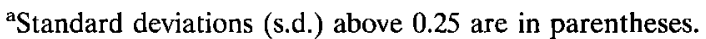



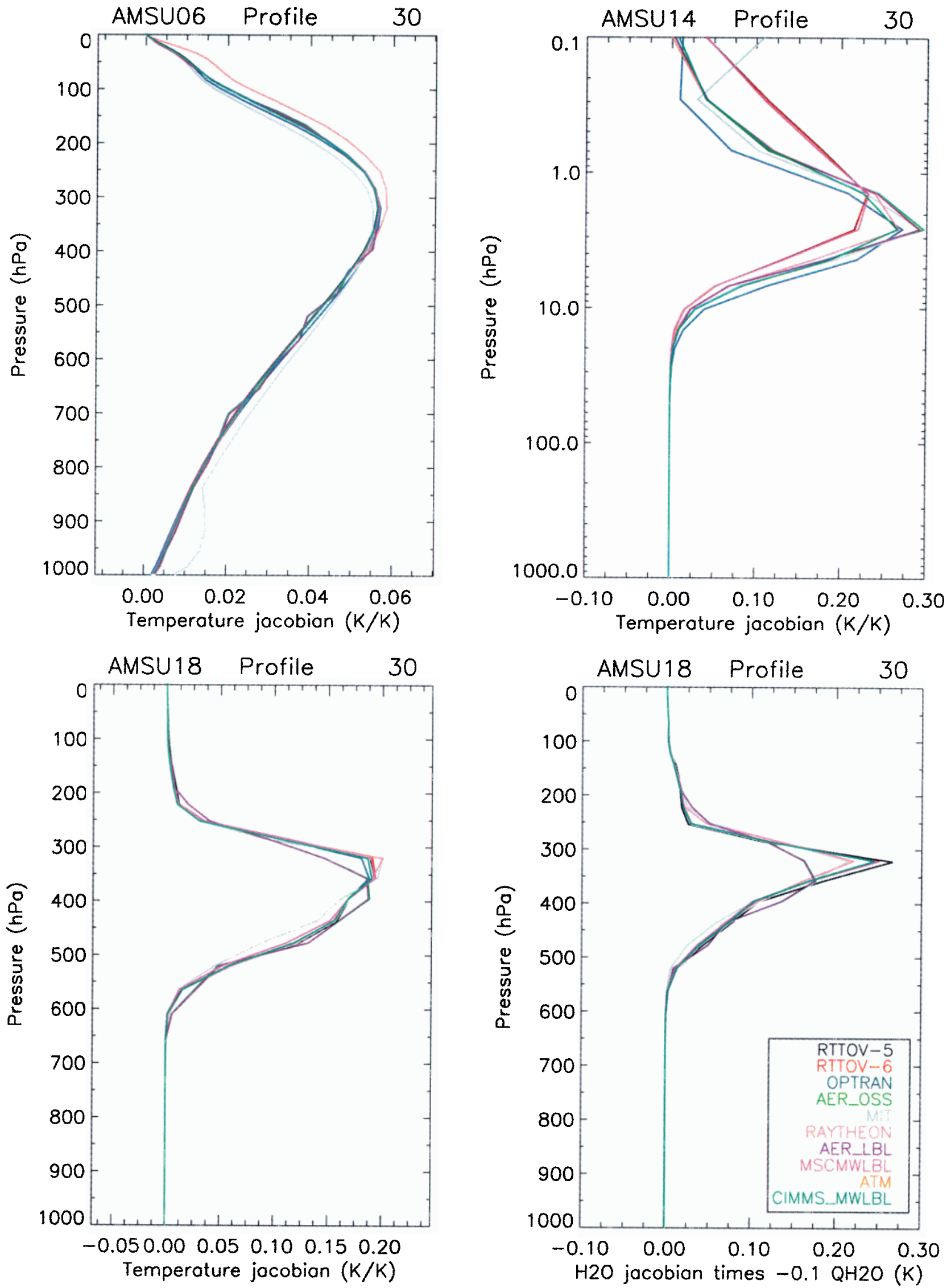

Plate 3. AMSU-06, 14 and $18 \mathrm{~T}$ Jacobian and AMSU-18 $\mathrm{H}_{2} \mathrm{O}$ Jacobian profiles for the various MW models applied to atmospheric profile 30 . 
Table 9. Goodness of Fit Measure $M$ (no Units) of Temperature $(T)$ or Water Vapor $\left(\mathrm{H}_{2} \mathrm{O}\right)$ Jacobians for the Various Microwave Models Applied to Atmospheric Profile 30 in Each of the Four AMSU Channels $(6,10,14$, and 18)

\begin{tabular}{lccccc}
\hline & A-06 & A-10 & A-14 & A-18 & A-18 \\
\multicolumn{1}{c}{ Model } & $T$ & $T$ & $T$ & $T$ & H $_{2} \mathrm{O}$ \\
\hline RTTOV-5 & 0.6 & 2.4 & $(28.6)$ & 2.0 & 7.1 \\
RTTOV-6 & 0.6 & 2.4 & $(28.6)$ & 3.3 & 1.7 \\
OPTRAN & 2.7 & 1.7 & 17.5 & 1.7 & 0.6 \\
AER_OSS & 2.4 & 3.9 & 9.5 & 13.5 & $(26.5)$ \\
MIT & 6.2 & 12.8 & $(25.7)$ & 19.4 & 20.3 \\
RAYTHEON & 10.7 & 3.8 & 7.5 & 3.8 & 10.0 \\
AER_LBL & 2.5 & 3.6 & 8.4 & 13.5 & $(26.6)$ \\
MSCMWLBL & 0.4 & 0.6 & 5.1 & 3.0 & 1.6 \\
\hline
\end{tabular}

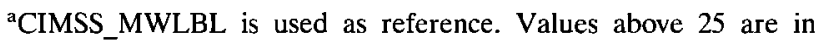
parentheses. ATM Jacobians data are not available.

related to the type of profile. In AMSU 14, OPTRAN has a negative bias of about $2 \mathrm{~K}$, which was eventually traced back to instability in the regression in one of the top layers. RTTOV-5 and 6 have occasional large positive differences (up to $4 \mathrm{~K}$ ) in some profiles. The largest differences occur in atmospheric profiles with the largest temperature gradients in the stratosphere (between $10 \mathrm{hPa}$ and $0.5 \mathrm{hPa}$, the temperature in-
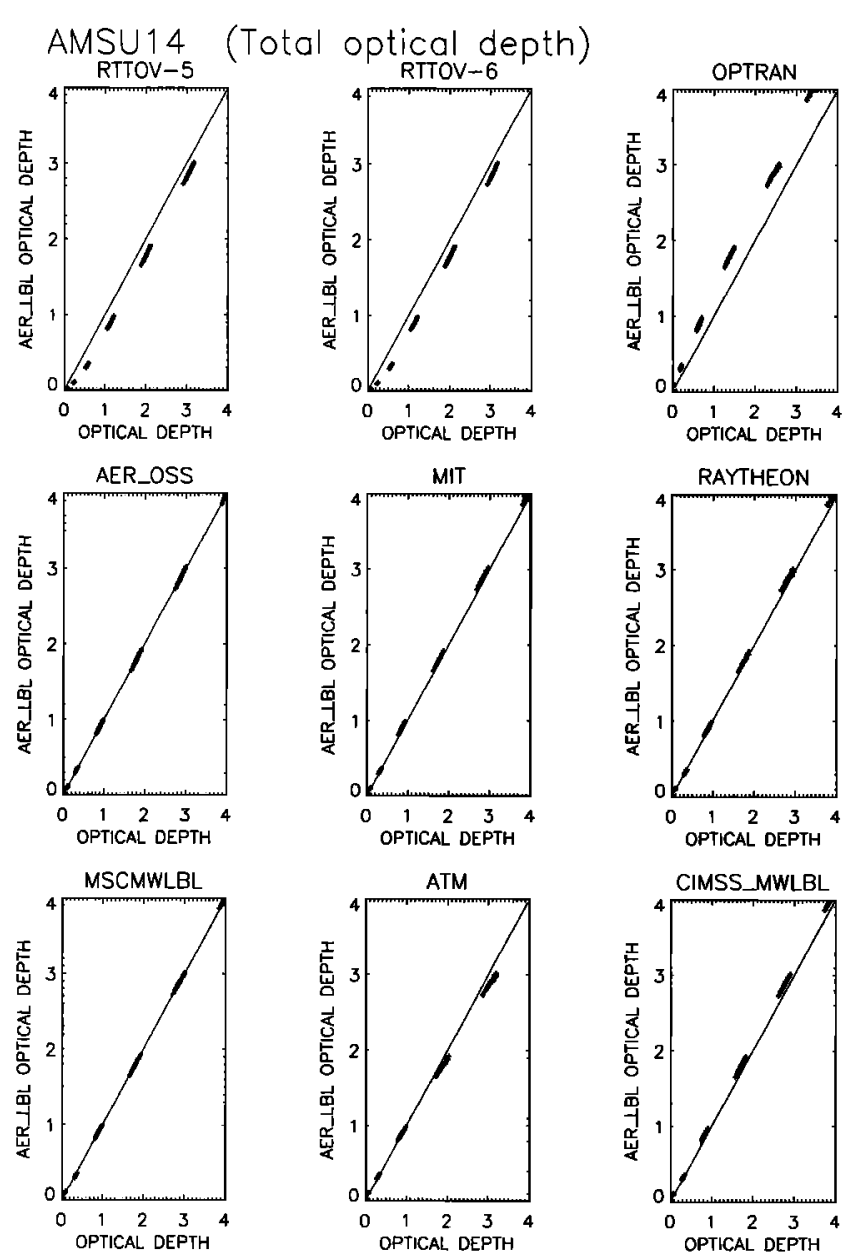

Figure 5. Scatterplot of AMSU-14 AER LBL TOA optical depths versus those of the other MW models obtained from all profiles and levels. creases by more than $45 \mathrm{~K}$ for atmospheres such as $3,5,12,13$, and 24). The reason for this difference is thought to be due to the inclusion of the Zeeman effect for RTTOV-5 and 6 which only manifests itself for profiles with large temperature gradients in the stratosphere as top-of-atmosphere radiances are only sensitive to transmittance differences where the layers are not isothermal. RTTOV was the only model that included this effect, and so simulations were performed using the MSCMWLBL model (which is the LBL model on which RTTOV is based in the microwave) with and without the Zeeman effect included. The results showed that a mean bias of $0.4 \mathrm{~K}$, $\mathrm{SD}$ of $1.1 \mathrm{~K}$, and a maximum difference of $3.2 \mathrm{~K}$ is obtained for the differences in the profile set when the effect is included or not which explains the larger differences for RTTOV seen in Table 8 and Figure 4 for AMSU 14. For the other AMSU channels the effect is negligible. For OPTRAN the profiles with large stratospheric temperature gradients also show differences but of opposite sign. The spread among models is more uniform in AMSU 18, with the largest differences for models ATM, RTTOV-6, MSCMWLBL, and RAYTHEON in the three driest atmospheres: 8,40 , and 42 .

\subsection{Jacobians and Transmittances}

Plate 3 shows examples of MW Jacobians and Table 9 lists values of $M$ computed with respect to CIMSS_MWLBL. As seen in Plate 3, RAYTHEON differs the most in AMSU 06, leading to a value of $M$ near 11 due to higher Jacobian values above $300 \mathrm{hPa}$. In all four panels of Plate 3, the MIT Jacobian appears slightly shifted downward compared to other models. A more subtle deficiency is noted for the AER models in the AMSU-06 Jacobian, with small oscillations that are likely due to the vertical interpolation (also noticeable in the AMSU-18 $\mathrm{H}_{2} \mathrm{O}$ Jacobian). RTTOV-6 is clearly an outsider in AMSU 14 because it considers the Zeeman effect as explained above. MIT and OPTRAN Jacobians are both placed lower in the atmosphere, resulting in relatively high $M$ values. In AMSU 18 the AER_OSS and AER_LBL model Jacobians peak lower than the others by about $40 \mathrm{hPa}$, resulting in values of $M$ of about 14 for the $\mathrm{T}$ Jacobian and 27 for the $\mathrm{H}_{2} \mathrm{O}$ Jacobian. The $\mathrm{H}_{2} \mathrm{O}$ Jacobian peak is less sharp and displays a distinctly lower magnitude $(0.18 \mathrm{~K}$ versus $0.30 \mathrm{~K})$. A relatively good agreement in BT does not always transfer into a good agreement in the Jacobians. This apparent contradiction is resolved if the cause of the differences is identified as the vertical interpolation of the Jacobian. Only a complete examination covering BTs, Jacobians, and transmittances gives confidence on the robustness and correct physical behavior of a given model under all circumstances.

Figure 5 shows total optical depth scatterplots for AMSU 14 with AER LBL as reference. Each group of points represents the optical depth from a given level to the TOA for the first eight levels (Table 4). The uniform oxygen concentration causes discrete grouping of the optical depth values. Optical depths near 4.0 correspond to those from the eighth level near $10 \mathrm{hPa}$, those near 3.0 are from the seventh level near $7 \mathrm{hPa}$ and so on. For all models the scatter is small. RTTOV-5 and RTTOV-6 are characterized by higher optical depths (due to the inclusion of the Zeeman effect), while the reverse is true for OPTRAN. For these models, a simple linear adjustment would not be sufficient to align with the reference since the pattern is not linear. As expected, AER_OSS follows AER_LBL very closely. MSCMWLBL is also in line with AER_LBL.CIMSS_MWLBL has slightly lower optical depth, 
as does RAYTHEON and MIT. ATM optical depths diverge noticeably from AER_LBL values as the optical depth increases.

\section{Conclusion}

There is a need to better understand the strengths and limitations of current RTMs. This study addressed that issue by inviting scientists to provide modeling results for a representative ensemble of HIRS and AMSU channels. BTs, transmittances, and Jacobians were evaluated. The main results can be summarized as follows:

1. IR LBLs typically agree between themselves to within $0.05-0.15 \mathrm{~K}$ in TOA BT. The same applies to MW LBLs except for one model in AMSU 14 and 18. However, systematic HIRS and AMSU biases as large as $0.5 \mathrm{~K}$ were noted.

2. Differences among IR LBLs are often largest for warmest and wettest atmospheres, notably for HIRS 10, 12, and 15. A detailed study on the air mass dependence of bias remains to be done.

3. IR NB models do not necessarily perform better than BB models because they are not tuned to fit an LBL. Similarly, $\mathrm{BB}$ models not tuned to an LBL but rather to a NB model (for convenience reasons) are at a disadvantage. Clearly, close links between BB and LBL modelers are necessary. Parameterizations that vary slowly with wavelength, such as those for the $\mathrm{H}_{2} \mathrm{O}, \mathrm{O}_{2}$, and $\mathrm{N}_{2}$ continua, can be implemented in BB models in a manner very similar to that in the LBL model.

4. The desired accuracy of $0.25 \mathrm{~K} \mathrm{SD}$ or better for fast IR models is achieved in various channels by various models, but no individual model reaches that level of accuracy in all channels. Since NWP centers prefer to rely on a single RTM in data assimilation, some combination of the best modeling approaches appears desirable.

5. Fast MW models can reproduce the corresponding LBL results with an accuracy of $0.10 \mathrm{~K} \mathrm{SD}$ in all air masses. In the microwave the main issue is therefore the accuracy of the LBL models.

6. The Jacobian study proved very useful in detecting bugs and potentially important inconsistencies. In general, Jacobians are quite smooth. The presence of kinks often points to known dangers of regression such as out-of-limits profiles (e.g., very low humidity in the stratosphere). Guaranteed continuity in level-to-TOA transmittance is important. The models need to be able to reproduce the amplitude and level of maximum amplitude of the Jacobian.

7. The interpolation between calculation and output levels creates Jacobian errors that may have important consequences.

8. Examination of optical depth scatterplots pertaining to specific gases reveals detailed information on the nature of differences between models. It identifies the gas most responsible for the differences. The magnitude and shape of the scatter is indicative of the potential accuracy. A nonlinear difference pattern implies a need for major changes to the transmittance formulation.

Other intercomparisons similar to this one will be needed for the evaluation of fast models pertaining to narrow IR channels such as those soon to be available from IASI (Infrared Atmospheric Sounding Interferometer) (scheduled for 2005, $\sim 8000$ channels at $0.25 \mathrm{~cm}^{-1}$ ) or AIRS (Atmospheric Infrared Sounder) (scheduled for 2001, $\sim 2370$ channels at 1 $\mathrm{cm}^{-1}$ ). We recommend for such future intercomparisons the following: (1) to obtain transmittance and Jacobians pertaining to all active gases, (2) to extend the validation to at least another viewing angle such as $60^{\circ}$ (the maximum angle for cross scanners or geostationary satellite retrievals), (3) to extend the validation to downward radiances in order to evaluate separately the surface reflection term (surface emissivity nonunity, with spectral variation), and (4) to compute if possible some channel BTs on global maps at reduced spatial resolution to better identify air-mass-dependent biases.

Desirable characteristics of fast models include (1) an accuracy of $0.25 \mathrm{~K}$ or better in all channels (or instrument noise level if it is greater), (2) minimization of air-mass-dependent biases, (3) specific transmittance profiles and analytical Jacobians for all active gases, (4) direct calculations on any vertical coordinate, and (5) easy adaptation to new instrument characteristics.

From the LBL modeling viewpoint, efforts should be made to better understand TOA BT differences among models in excess of $0.15 \mathrm{~K}$. One area of uncertainty remains the water vapor continuum. Because this parameterization attempts to match observed and modeled spectra, it will differ for LBL models that treat the wings and/or shapes of the absorption lines differently. In other words, the treatment of lines and continua requires consistency. Another requirement, of a more practical nature, is the development of faster LBL models of sufficient accuracy and speed to meet the ever increasing demand for reference calculations. Because only a handful of individuals maintain LBL codes, common sets of profiles should be defined, and LBL computations on these profiles advertised and shared. Clearly, one of the most useful outcomes of this work is the comprehensive data set produced which can be used by RT model developers to compare with their own model calculations.

Acknowledgments. We thank A. Chedin and R. Armante for the development of model 4A, D. P. Edwards for that of GENLN2, S. Tjemkes for that of SYNSATRAD, S. A. Clough and M. J. Iacono for that of LBLRTM, and L. Strow and T. Wehr for that of HFFP. The MSC web site is located at www.cmc.ec.gc.ca/rpn/arma; see the intercomparison section for full results on this study. For the latest RTTOV documentation, see http://www.metoffice.com/sec5/NWP/NWPSAF/ rtm.

\section{References}

Anderson, G. P., S. A. Clough, F. X. Kneizys, J. H. Chetwood, and E. P. Shettle, AFGL atmospheric constituent profiles $(0-120 \mathrm{~km})$, AFGL Tech. Rep., AFGL-TR-0110, 48 pp., Air Force Geophys. Lab., Bedford, Mass., 1986.

Barrett, A. H., and V. K. Chung, High-altitude water vapor abundance from ground-based microwave observations, J. Geophys. Res., 67, 4259-4266, 1962.

Berk, A., L. S. Bernstein, and D. C. Robertson, MODTRAN: A moderate resolution model for LOWTRAN 7, Tech. Rep. GL-TR-890122, 38 pp., 1989. (Available from Spectral Sciences Inc., Burlington, Mass.)

Chedin, A., H. Fischer, K. Kunzi, D. Spankuch, and N. A. Scott, Report on the ITRA/IRC Campaign and Workshop, edited by A. Chedin et al., Univ. of Maryland, College Park, Md., 1986. 1988.

Cheruy, F., N. A. Scott, R. Armante, B. Tournier, and A. Chedin, Contribution to the development of radiative transfer models for high spectral resolutions in the infrared, J. Quant. Spectrosc. Radiat. Transfer, 53, 597-611, 1995.

Clough, S. A., and M. J. Iacono, Line-by-line calculation of atmospheric fluxes and cooling rates, 2, Applications to carbon dioxide, ozone, methane, nitrous oxide, and the halocarbons, J. Geophys. Res., 100, 16,519-16,535, 1995. 
Clough, S. A., F. X. Kneizys, and R. W. Davies, Line shape and the water vapor continuum, Atmos. Res., 23, 229-241, 1989.

Clough, S. A., M. J. Iacono, and J. L. Moncet, Line-by-line calculations of atmospheric fluxes and cooling rates: Application to water vapor, J. Geophys. Res., 97, 15,761-15,785, 1992.

Edwards, D. P., GENLN2: A general line-by-line atmospheric transmittance and radiance model, NCAR Tech. Note, NCAR/TN367+STR, Natl. Cent. for Atmos. Res., Boulder, Colo., 1992.

Ellingson, R. G., J. Ellis, and S. B. Fels, Intercomparison of Radiation Codes used in Climate Models (ICRCCM): Long-wave results, $J$. Geophys. Res., 96, 8929-8953, 1991.

Engelen, R., and G. L. Stephens, Characterization of water vapour retrievals from infrared TOVS radiances and microwave SSM/T-2 radiances, Q. J. R. Meteorol. Soc., 125, 331-351, 1999.

Eyre, J. R., G. A. Kelly, A. P. McNally, E. Andersson, and A. Persson, Assimilation of TOVS radiance information through one-dimensional variational analysis, Q. J. R. Meteorol. Soc., 119, 1427-1463, 1993.

Falcone, V. J., L. W. Abreu, and E. P. Shettle, Atmospheric attenuation of millimeter and submillimeter waves: Models and computer code, Tech. Rep., Hanscom Air Force Base, Mass., 1979.

Garand, L., Sensitivity of retrieved atmospheric profiles from infrared radiances to physical and statistical parameters of the data assimilation system, Atmos. Ocean, 38, 431-455, 2000.

Garand, L., D. S. Turner, C. Chouinard, and J. Hallé, A physical formulation of atmospheric transmittances for the massive assimilation of satellite infrared radiances, J. Appl. Meteorol., 38, 541-554, 1999.

Jacquinet-Husson, N., et al., The 1997 spectroscopic GEISA databank, J. Quant. Spectrosc. Radiat. Transfer, 62, 205-254, 1999.

Joiner, J., H.-T. Lee, L. L. Strow, P. K. Bhartia, S. Hannon, A. J. Miller, and L. G. Rokke, Radiative transfer in the $9.6 \mu \mathrm{m}$ HIRS ozone channel using collocated SBUV-determined ozone abundances, J. Geophys. Res., 103, 19,213-19,219, 1998.

Key, J., Streamer user's guide, Tech. Rep. 96-01, 85 pp., Dep. of Geogr., Boston Univ., Boston, Mass., 1997.

Liebe, H., MPM-An atmospheric millimeter wave propagation model, Int. J. Infrared Millimeter Waves, 10, 631-650, 1989.

Liebe, H., P. W. Rosenkranz, and G. A. Hufford, Atmospheric $60 \mathrm{GHz}$ oxygen spectrum: New laboratory measurements and line parameters, J. Quant. Spectrosc. Radiat. Transfer, 48, 629-643, 1992.

Liebe, H., G. A. Hufford, and M. G. Cotton, Propagation modeling of moist air and suspended water/ice particles at frequencies below $1000 \mathrm{GHz}$, in Proceedings of the AGARD 52nd Specialists' Meetıng of the Electromagnetic Wave Propagation Panel, Advis. Group for Aerosp. Res. and Dev., Brussels, Belgium, 1993.

McMillin, L. M., and H. E. Fleming, Atmospheric transmittance of an absorbing gas: A computationally fast and accurate transmittance model for absorbing gases with constant mixing ratios in inhomogeneous atmospheres, Appl. Opt., 15, 358-363, 1976.

McMillin, L. M., L. J. Crone, and T. J. Kleespies, Atmospheric transmittance of an absorbing gas, 5, Improvements to the OPTRAN approach, Appl. Opt., 34, 8396-8399, 1995.

Pardo, J. R. E., E. Serabyn, and J. Cernicharo, Submillimeter atmospheric transmission measurements on Mauna Kea during extremely dry El Nino conditions: Implications for broadband opacity contributions, J. Quant. Spectrosc. Radiat. Transfer, 68, 419-433, 2001 .

Pardo, J. R. E., J. Cernicharo, and E. Serabyn, Atmospheric transmission at microwaves (ATM): An improved model for $\mathrm{mm} / \mathrm{submm}$ applications, IEEE Trans. Antennas Propag., in press, 2001b.

Rosenkranz, P. W., Shape of the $5 \mathrm{~mm}$ oxygen band in the atmosphere, IEEE Trans. Antennas Propag., AP-23, 498-506, 1975.

Rosenkranz, P. W., A rapid atmospheric transmittance algorithm for microwave sounding channels, IEEE Trans. Geosci. Remote Sens., $33,1135-1140,1995$.
Rosenkranz, P. W., A comparison of measurements and models, Radıo Sci., 33, 919-928, 1998.

Rothman, L. S., et al., The HITRAN molecular spectroscopic database and HAWKS (HITRAN atmospheric workstation): 1996 edition, $J$. Quant. Spectrosc. Radiat. Transfer, 60, 665-710, 1998.

Saunders, R. W., M. Matricardi, and P. Brunel, An improved fast radiative transfer model for assimilation of satellite radiance observations, Quart. J. R. Meteorol. Soc., 125, 1407-1425, 1999.

Scott, N. A., and A. Chedin, A fast line-by-line method for atmospheric absorption computation: The Automated Atmospheric Absorption Atlas, J. Appl. Meteorol., 20, 802-812, 1981.

Sienkiewicz, M., The GLA TOVS rapid algorithm forward radiance modules and Jacobian version 1.0, DAO Off. Note 86-08, NASA 1996. (Available from DAO, Goddard Space Flight Center, Greenbelt, Md.)

Soden, B., et al., An intercomparison of radiation codes for retrieving upper-tropospheric humidity in the $6.3 \mu \mathrm{m}$ band: A report from the first GVaP workshop, Bull. Am. Meteorol. Soc., 81, 797-808, 2000.

Susskind, J., J. Rosenfield, and D. Reuter, An accurate radiative transfer model for use in the direct physical inversion of HIRS and MSU temperature sounding data, J. Geophys. Res., 88, 8550-8568, 1983.

Tjemkes, S., and J. Schmetz, Synthetic satellite radiances using the radiance sampling method, J. Geophys. Res., 102, 1807-1818, 1997.

Tournier, B., R. Amante, and N. A. Scott, Stransac-93 and 4A-93, Développement et validation des nouvelles versions des codes de transfert radiatif pour application au projet IASI, Internal Note 201, 43 pp., Lab. de Meteorol. Dyn., Palaiseau, France, 1995.

Turner, D. S., Absorption coefficient estimation using a twodimensional interpolation procedure, J. Quant. Spectrosc. Radiat. Transfer, 53, 633-637, 1995a.

Turner, D. S., A fast line-by-line radiative transfer model for TOVS radiance/transmittance studies, in Technical Proceedings of the Eighth International TOVS Study Conference, pp. 465-473, Queenstown, New Zealand, 1995b.

Weinreb, M. P., H. E. Fleming, L. M. McMillin, and A. C. Neuendorffer, Transmittances for the TIROS Operational Vertical Sounder, NOAA Tech. Rep., NESS 85, 60 pp., Natl. Oceanıc and Atmos. Admin., Washington, D. C., 1981.

J. Bates and D. Jackson, NOAA/ERL, 325 Broadway, Boulder, CO 80303

S. Boukabara and J.-L. Moncet, AER, 840 Memorial Drive, Cambridge, MA 02139 .

P. Brunel, Meteo-France, Lannion, France.

F. Chevallier, ECMWF, Reading, England, UK.

G. Deblonde, L. Garand, and M. Larocque, MSC, 2121 TransCanada Highway, Dorval, Qc., Canada, H9P 1J3. (louis.garand@ ec.gc.ca)

R. Engelen, Dept. of Atmospheric Science, Colorado State Univ., Fort Collins, CO 80523

M. Hollingshead and D. S. McKague, Raytheon, Aurora, CO 80011. G. Jedlovec, NASA MSFC, Huntsville, AL 35805.

J. Joiner, NASA DAO, Greenbelt, MD 20771.

T. Kleespies and L. McMillin, NOAA NESDIS, Camp Springs, MD 20746-4304.

J. R. Pardo, California Institute of Technology, Pasadena, CA 91125

P. J. Rayer and R. Saunders, Met Office, Bracknell, England, UK. E. Salathe, Univ. of Washington, Seattle, WA 98195.

N. A. Scott, CNRS/LMD, Palaiseau, France.

D. S. Turner, MSC, Downsview, Ont., Canada M3H5T4.

P. Van Delst and H. Woolf, Univ. of Wisconsin, Madison, WI 53706.

(Received November 21, 2000; revised March 23, 2001; accepted March 29, 2001.) 